\title{
An extended interpretation of the free-fall piezocone test in clay
}

S.H. Chow ${ }^{1}$, C.D. O’Loughlin ${ }^{2}$, D.J. White ${ }^{3}$, M.F. Randolph ${ }^{4}$

Words: 5856 (main text), Figures: 16, Tables: 5

${ }^{1}$ Corresponding Author (BEng, MEng, PhD)

Research Fellow, Centre for Offshore Foundation Systems

The University of Western Australia

35 Stirling Highway, Crawley WA 6009, Perth, Australia

Phone: +61864886930

Fax: +61864881044

E-mail: shiaohuey.chow@uwa.edu.au

${ }^{2}$ Associate Professor, Centre for Offshore Foundation Systems (BEng, $\mathrm{PhD}$ )

The University of Western Australia

35 Stirling Highway, Crawley WA 6009, Perth, Australia

Phone: +61864886488

Fax: +61864881044

E-mail: conleth.oloughlin@uwa.edu.au

${ }^{3}$ Shell EMI Chair in Offshore Engineering, Centre for Offshore Foundation Systems (MA, MEng, $\mathrm{PhD}$ )

The University of Western Australia

35 Stirling Highway, Crawley WA 6009, Perth, Australia

Phone: +61864883086

Fax: +61 864881044

E-mail: david.white@uwa.edu.au

${ }^{4}$ Fugro Chair in Geotechnics, Centre for Offshore Foundation Systems (MA, PhD, FAA, FREng, FRS, FTSE, FIEAust, CPEng)

The University of Western Australia

35 Stirling Highway, Crawley WA 6009, Perth, Australia

Phone: +61864883075

Fax: +61 864881044

E-mail: mark.randolph@uwa.edu.au 


\begin{abstract}
Seabed strength may be determined rapidly using free-fall penetrometers as the tool is simply released from above the sea-floor and penetrates under gravity into the seabed. The speed and ease of deployment relative to conventional 'push-in' penetrometers is attractive, with the trade-off of more complex interpretation. This paper considers two approaches for deducing the undrained shear strength from a slender conical tipped penetrometer. The first requires as input only the vertical acceleration of the penetrometer, where the soil strength is determined indirectly by considering the various forces acting on the penetrometer and solving the equation of motion. The second determines the undrained shear strength more directly by combining tip load cell and u2 pore pressure measurements. In both cases adjustments for drag resistance and strain-rate effects are necessary, to deduce a strength compatible with that determined from the equivalent push-in penetrometer test. Application of both methods to a series of centrifuge tests in normally consolidated kaolin clay reveal that the direct method - using the tip load cell and $\mathrm{u}_{2}$ pore pressure measurements - is much more reliable and can produce strength profiles that are within $10 \%$ of those obtained from push-in piezocone tests, compared with variations of up to $75 \%$ for the indirect accelerometer based method, which requires additional assumptions. The centrifuge study also provides direct quantification of the strain rate enhancement of tip and shaft resistance, revealing much higher strain rate dependency for shaft resistance than is typically allowed for.
\end{abstract}

\title{
Keywords:
}

Free-fall penetrometer, strain-rate, dynamic penetration, offshore 


\section{Notation}

\begin{tabular}{|c|c|}
\hline$A_{\mathrm{t}}, A_{\mathrm{s}}$ & penetrometer tip area, shaft area \\
\hline$a$ & acceleration \\
\hline$B_{\mathrm{q}}$ & pore pressure parameter \\
\hline$C_{\mathrm{D}}$ & drag coefficient \\
\hline$d, d_{\mathrm{ref}}$ & penetrometer diameter, reference penetrometer diameter \\
\hline FFP & free-fall penetrometer \\
\hline$F_{\mathrm{b}}$ & buoyancy force $(\mathrm{N})$ \\
\hline$F_{\mathrm{D}}$ & hydrodynamic drag force $(\mathrm{N})$ \\
\hline$F_{\mathrm{c}}$ & cone tip force measured by tip load cell $(\mathrm{N})$ \\
\hline$F_{\mathrm{s}}$ & shaft force measured by shaft load cell or friction force $(\mathrm{N})$ \\
\hline$F_{\text {tip }}$ & tip force $(\mathrm{N})$ \\
\hline$f_{\mathrm{s}}$ & shaft friction resistance $(\mathrm{kPa})$ \\
\hline$f_{\mathrm{s}(\mathrm{s})}, f_{\mathrm{s}(\mathrm{d})}$ & static and dynamic shaft friction resistance $(\mathrm{kPa})$ \\
\hline$G_{\mathrm{s}}$ & specific gravity \\
\hline$g$ & Earth's gravitational acceleration, $9.81 \mathrm{~m} / \mathrm{s}^{2}$ \\
\hline$L$ & length of FFP \\
\hline $\mathrm{LL}$ & Liquid limit \\
\hline MEMS & micro-electro mechanical system \\
\hline$m$ & penetrometer mass \\
\hline$m^{\prime}$ & added soil mass accelerating or decelerating with the FFP \\
\hline$m_{\mathrm{c},} m_{\mathrm{s}}$ & mass of material below the tip and sleeve load cells respectively \\
\hline$N_{\mathrm{kt}}$ & resistance factor for piezocone \\
\hline$N_{\text {T-bar }}$ & resistance factor for T-bar penetrometer taken as 10.5 \\
\hline$p^{\prime}$ & mean effective stress \\
\hline PL & Plastic limit \\
\hline$q_{\mathrm{c}}$ & cone tip resistance $(\mathrm{kPa})$ \\
\hline$q_{\mathrm{b}}$ & buoyancy resistance $(\mathrm{kPa})$ \\
\hline$q_{\mathrm{D}}$ & inertial drag resistance $(\mathrm{kPa})$ \\
\hline$q_{\text {net }}$ & net cone resistance $(\mathrm{kPa})$ \\
\hline$q_{\text {net(s) }}, q_{\text {net(d) }}$ & static and dynamic net cone resistance $(\mathrm{kPa})$ \\
\hline$R_{\mathrm{f}(\mathrm{tip}),} R_{\mathrm{f}(\text { shaft })}$ & rate effects or strain rate factor for tip and shaft resistance \\
\hline$S u$ & undrained shear strength \\
\hline
\end{tabular}




\begin{tabular}{|c|c|}
\hline$S \mathrm{u}(\mathrm{avg})$ & average undrained shear strength over the length of embedded FFP \\
\hline$u_{2}, u_{3}$ & pore pressure measured at cone shoulder and top of friction sleeve \\
\hline$\Delta u_{2}$ & excess pore pressure, $u_{2}-u_{f}$ \\
\hline$\Delta u_{\mathrm{i}}$ & maximum excess pore pressure, $u_{i}-u_{f}$ \\
\hline$V_{s}$ & volume of soil displaced by the FFP \\
\hline$v, v_{\mathrm{i}}, v_{\mathrm{ref}}$ & penetration velocity, impact velocity, reference velocity \\
\hline$W_{\mathrm{b}}$ & penetrometer submerged self-weight \\
\hline$z$ & penetration depth \\
\hline$\alpha$ & interface friction ratio \\
\hline$\alpha_{\text {cone }}$ & unequal area ratio \\
\hline$\beta_{\text {tip },} \beta_{\text {shaft }}$ & power-law rate parameter for tip and shaft resistances respectively \\
\hline$M, \Gamma, \lambda, \kappa$ & critical state parameters \\
\hline$\rho_{s}, \rho^{\prime}$ & saturated and submerged density of soil \\
\hline$\phi^{\prime}$ & angle of internal friction \\
\hline$\sigma_{v o}$ & vertical overburden stress \\
\hline$\sigma_{v}^{\prime}$ & vertical effective stress \\
\hline$\tau_{\text {(avg) }}$ & average shear stress on the FFP shaft \\
\hline$\dot{\gamma}, \dot{\gamma}_{r e f}$ & soil strain rate, reference strain rate \\
\hline
\end{tabular}

\section{INTRODUCTION}

Free-fall penetrometers (FFPs) are projectiles that free fall from above the seafloor and subsequently self-penetrate the seabed. Measurements made during penetration allow the seabed strength to be determined. Recent work (e.g. Mulukutla 2009; Chow et al. 2014) has demonstrated that these devices can also measure the coefficient of consolidation if the penetrometer remains in the seabed after installation to measure the dissipation of excess pore pressure. In this respect they are analogous to their 'push-in' counterparts, the piezocone and piezoball, which also measure soil strength and consolidation coefficients. However, unlike push-in penetrometers that typically require deployment of a seabed reaction frame from a geotechnical survey vessel, free-fall penetrometers can be deployed from smaller and less 
expensive vessels. Furthermore, as they allow coverage of a large seabed area in a relatively short time frame, they have particular potential in supplementing data from push-in penetrometer tests that are undertaken at large spatial intervals, reducing the uncertainty associated with spatial variability.

Most free-fall penetrometers have geometries that resemble their 'push-in' counterparts. However, the velocity at impact with the seabed is typically up to $10 \mathrm{~m} / \mathrm{s}$ depending on geometry and drop height. which is almost three orders of magnitude higher than push-in penetrometers, inserted at a standard rate of $0.02 \mathrm{~m} / \mathrm{s}$.

The high velocities present difficulties in interpreting the dynamic data to establish a soil strength that is equivalent to that measured in a constant (and much lower) velocity push-in test. This issue, and the apparent different effects of strain rate on shaft friction and tip bearing (Steiner et al. 2014; Chow et al. 2014), have impeded wider take-up of this technology until the interpretation methods are more certain. However, the geotechnical framework for dynamic penetrometer resistance has advanced significantly in recent years from extensive studies on FFPs (e.g. Young et al. 2011; Buhler \& Audibert 2012; Steiner et al. 2014; Chow \& Airey 2013, 2014; Chow et al. 2014), dynamically-installed anchors (e.g. O’Loughlin et al. 2004, 2009, 2013; Blake and O'Loughlin, 2015; Sabetamal et al. 2016) and submarine runout impact on pipelines (e.g. Randolph and White, 2012; Sahdi et al., 2014). There is now a more mature understanding of the soil response to the penetration of solid bodies at very high velocities.

Strategies for deducing the undrained shear strength, $s \mathrm{u}$, from FFP measurements depend on the FPP geometry and the extent and type of instrumentation included on the FPP. Where the instrumentation is limited to accelerometers, or for spherical FFPs (Morton et al. 2015), $s_{\mathrm{u}}$ is derived indirectly from acceleration measurements via the equation of motion. For the more typical slender conical-tipped FFP geometry shown in Fig. 1a, $s_{\mathrm{u}}$ may also be derived indirectly 
from the acceleration measurements, making allowance for the shaft resistance component, or directly from tip load cell measurements (Fig. 1b). The latter methods matches a conventional cone penetrometer but requires allowances for the higher (and varying) penetration rate.

This paper compares the performance of both the indirect and direct methods in deducing soil strength profiles from a free-fall cone penetrometer through comparison with equivalent profiles from push-in tests. The techniques are outlined first, including a new direct approach using tip load cell and $\mathrm{u}_{2}$ pore pressure measurements. The relative merits of the indirect and direct methods are then assessed by comparison with centrifuge test results.

\section{DETERMINING UNDRAINED SHEAR STRENGTH FROM FFP DATA}

\section{Indirect approach: accelerometer method}

The indirect approach uses as input only the vertical acceleration, $a$, of the FFP. The net force on the FFP during penetration in soil can then be calculated from the sum of the forces acting on it (Fig. 1a):

$$
\left(m+m^{\prime}\right) a=W_{b}-F_{t i p}-F_{s}-F_{D}-F_{b}
$$

where $m$ is the FFP mass and the forces (shown in Fig. 1a) are the submerged weight of the FFP in water, $W_{b}$, bearing resistance at the tip (due to the soil strength), $F_{\text {tip }}$, frictional resistance along the shaft, $F_{\mathrm{s}}$, drag resistance, $F_{\mathrm{D}}$, and a buoyancy force, $F_{\mathrm{b}}$, equal to the effective weight of the displaced soil. An added mass term, $m^{\prime}$, is included on the left hand side of Equation 1 to account for the soil that is accelerated or decelerated with the FFP as it accelerates or decelerates. However, for long slender FFPs, this added mass is limited to a small zone of soil at the tip and, when fully embedded in soil, at the rear of the FFP. This is sufficiently small that it may be ignored (Beard 1981, Shelton et al. 2011; Blake \& O’Loughlin, 2015).

Tip and shaft resistances are expressed as: 


$$
\begin{gathered}
F_{\text {tip }}=R_{f(t i p)}\left(s_{u} N_{k t} A_{t}\right) \\
F_{s}=R_{f(\text { shaft })}\left(\alpha s_{u(\text { avg })} A_{s}\right)
\end{gathered}
$$

where $A_{\mathrm{t}}$ and $A_{\mathrm{s}}$ are the tip and shaft areas respectively, $N_{\mathrm{kt}}$ is the cone resistance factor, $\alpha$ is the interface friction ratio (i.e. $\alpha=\tau_{(\mathrm{avg})} / \mathrm{su(avg)}$ where $\tau_{(\mathrm{avg})}$ is the average shear stress on the shaft), $s_{\mathrm{u}}$ is the undrained shear strength at the cone tip, and $s_{\mathrm{u}(\mathrm{avg})}$ is the average strength over the length of the embedded shaft. These strengths are defined at a 'reference' penetration rate (or a representative strain rate in the soil), taken in practice as that of a static penetration test.

The strain rate functions, $R_{\mathrm{f}(\mathrm{tip})}$ and $R_{\mathrm{f}(\text { shaft })}$ are introduced in Equations 2 and 3 to account for the well-known dependence of soil strength on strain rate. This may be modelled using either a semi-logarithmic law, an inverse hyperbolic sine law or a power law (including the HerschelBulkley formulation widely used in modelling rate effects for solid objects moving through soft soils, e.g. Zakeri et al. 2008, Raie \& Tassoulas 2009, Zhu \& Randolph 2011). The power law function has generally been preferred as it is found to capture rate effects better than logarithmic functions over large ranges in strain rate (Biscontin \& Pestana 2001), also including for dynamically installed anchors that have a similar geometry to the CPT (O’Loughlin et al. 2013). The rate functions may therefore be expressed as:

$$
\begin{gathered}
R_{f(t i p)}=\left(\frac{\dot{\gamma}}{\dot{\gamma}_{\text {ref }}}\right)^{\beta_{\text {tip }}}=\left(\frac{(v / d)}{(v / d)_{\text {ref }}}\right)^{\beta_{\text {tip }}} \geq 1 \\
R_{f(\text { shaft })}=\left(\frac{\dot{\gamma}}{\dot{\gamma}_{\text {ref }}}\right)^{\beta_{\text {shaft }}}=\left(\frac{(v / d)}{(v / d)_{\text {ref }}}\right)^{\beta_{\text {shaft }}} \geq 1
\end{gathered}
$$

where $\dot{\gamma}$ is the strain rate, $\dot{\gamma}_{\text {ref }}$ is the reference strain rate associated with the reference value of undrained shear strength and $\beta$ is a strain rate parameter. This parameter is typically in the range 0.03 to 0.08 when the power law is applied over no more than 2 to 3 orders of magnitude 
variation in strain rate (Biscontin \& Pestana 2001; Lehane et al. 2009; Low 2009; O'Loughlin et al. 2013).

For shearing around the cylindrical geometry of the FFP, the operational strain rate may be linked to the normalised velocity, $v / d$, where $v$ is the instantaneous velocity and $d$ is the diameter. The reference strain rate, and hence selection of $v_{\text {ref }}$ and $d_{\text {ref, }}$ should correspond to nominally undrained conditions, similar to those that are assumed to apply in the usual undrained interpretation of a push-in cone penetrometer test. For instance, selection of $v_{\text {ref }}=$ $0.02 \mathrm{~m} / \mathrm{s}$ and $d_{\text {ref }}=0.0357 \mathrm{~m}$ in Equations 4 and 5 would result in a back-figured strength that would be comparable to that measured by a $10 \mathrm{~cm}^{2}$ cone penetrated at the standard $0.02 \mathrm{~m} / \mathrm{s}$. The influence of $(v / d)_{\text {ref }}$ selection on the interpreted $s_{\mathrm{u}}$ is discussed later.

Separate values of rate parameter $\beta$ are required for the tip and the shaft to account for the greater rate effects observed for shaft resistance compared to tip resistance (Dayal et al. 1975; Steiner et al. 2014). The shear strain rate immediately adjacent to the shaft exceeds the nomalised velocity, $v / d$, by a factor that can be estimated analytically as described by Einav and Randolph (2006), and this factor must be considered when scaling from FFP resistance to soil strength at a given strain rate. However, since Equation (5) represents the ratio of shaft resistance at different penetration rates, no additional factor is required.

Calculation of $s_{\mathrm{u}}$ also requires elimination of drag and buoyancy resistance from the measured net force acting on the FFP. The inclusion of drag is essential in situations where very soft soil is encountered at the surface of the seabed, since this component of resistance can be comparable to the resistance from the soil strength (Boukpeti et al. 2012; Randolph \& White 2012; Sahdi et al. 2014). O’Loughlin et al. (2013) and Blake and O'Loughlin (2015) further showed that drag is the dominant resistance acting on a dynamically installed anchor in 
normally consolidated clay during initial embedment and typically to about $30 \%$ of the final penetration.

The drag resistance term is formulated as

$$
F_{D}=\frac{1}{2} \rho_{s} C_{D} A_{t} v^{2}
$$

where $\rho_{\mathrm{s}}$ is the saturated density of the soil and $C_{\mathrm{D}}$ is the drag coefficient, the value of which depends on the penetrometer geometry. For well-profiled slender geometries $C_{\mathrm{D}}=0.22$ is appropriate (O'Loughlin et al. 2013), and this parameter may be readily determined from the free-fall (in water) stage of the test using the acceleration measurements.

The soil buoyancy force is calculated as the effective weight of the displaced soil using the currently-submerged volume of the FFP in addition to the extra volume due to the cavity that may form in the wake of the penetrometer should the FFP fully bury in the seabed. It is expressed as:

$$
F_{b}=\rho^{\prime} V_{s} g
$$

where $\rho^{\prime}$ is the submerged density of the soil, $g$ is Earth's gravitational acceleration $\left(9.81 \mathrm{~m} / \mathrm{s}^{2}\right)$ and $V_{s}$ is the volume of soil displaced by the FFP.

The above equations allow the only unknown, $s_{\mathrm{u}}$, to be calculated at every instant in the time history recorded by the FPP instrumentation. This may then be translated into a profile of $s_{\mathrm{u}}$ with depth, $z$, using double numerical integration of the acceleration measurements to determine $z$. It may be necessary to pre-process the acceleration data due to any non-verticality of the device, as described in Blake et al. (2016).

This double integration requires an iterative approach because some terms vary with depth of penetration into the seabed, $z$ (specifically $V_{s}$ and $A_{s}$ ) or switch when the FFP is in water or soil 
$(z>0)$ (specifically $\left.F_{D}\right)$. The time history of vertical movement is known but not the corresponding vertical position (height above or depth within seabed). Therefore, an initial guess is required (for example, assuming the drop position is at $z=0$ ), followed by iteration in which the $h$ datum is varied until the calculated $s_{u}$ is zero for $z<0$.

\section{Direct approach: tip load cell method}

Where the FFP includes measurements of the cone tip resistance, $F_{\mathrm{c}}$ and pore pressure at cone shoulder position, $u_{2}$ (Fig. 1b), a direct approach is used in which $s_{\mathrm{u}}$ is determined from the dynamic cone tip resistance. Referring to Fig. 2, the tip load cell measurement $F_{\mathrm{c}}$, can be expressed as the measured tip stress $q_{\mathrm{c}}=F_{\mathrm{c}} / A_{\mathrm{t}}$, which comprises dynamic soil bearing resistance (due to soil strength), $q_{\text {tip }}$, drag resistance, $q_{\mathrm{D}}$ and changes in the soil buoyancy due to the selfweight of displaced soil, $q_{\mathrm{b}}$. Vertical equilibrium of the cone tip itself leads to:

$$
q_{c}+u_{2}\left(1-\alpha_{\text {cone }}\right)=q_{\text {tip }}+q_{b}+q_{D}
$$

where $q_{\text {tip }}=F_{\text {tip }} / A_{\mathrm{t}}, q_{\mathrm{b}}=F_{\mathrm{b}} / A_{\mathrm{t}}$ and $q_{\mathrm{D}}=F_{\mathrm{D}} / A_{\mathrm{t}} . F_{\text {tip }}, F_{\mathrm{b}}, F_{\mathrm{D}}$ are as defined previously in Equations 2, 6 (except $\rho_{\text {s }}$ is used instead of $\rho^{\prime}$ ) and 7 respectively, and $\alpha_{\text {cone }}$ is the unequal area ratio $=$ $A_{\mathrm{i}} / A_{\mathrm{t}}=d_{\mathrm{i}}{ }^{2} / d^{2}$ (and determined as 0.74 for the instrument used here). This term accounts for the area above the cone occupied by the pore pressure filter acted upon by the $u_{2}$ pore pressure.

Combining these definitions of $q_{\mathrm{c}}, q_{\mathrm{b}}$ and $q_{\mathrm{D}}$ with Equations 2, 6 and 7 allows Equation 9 to be written as

$$
q_{c}+u_{2}\left(1-\alpha_{\text {cone }}\right)=R_{f(t i p)} s_{u} N_{k t}+\rho_{s} g h+\frac{1}{2} \rho_{s} C_{D} v^{2}
$$

In Equation 9, the buoyancy term, $q_{\mathrm{b}}=\rho_{\mathrm{s}} g h$ is the overburden stress, $\sigma_{\mathrm{vo}}$ (where the FFP does not fully bury in the soil or the hole formed by the passage of the FFP remains open). The undrained shear strength can then be calculated directly from 


$$
S_{u}=\frac{q_{n e t(d)}}{R_{f(t i p)} N_{k t}}=\frac{q_{c}+u_{2}\left(1-\alpha_{\text {cone }}\right)-\sigma_{v o}-q_{D}}{R_{f(t i p)} N_{k t}}
$$

Equation 10 is almost identical to that used in the interpretation of push-in cone penetration resistance, although with the inclusion of the parameter $R_{\mathrm{f}(\mathrm{tip})}$ (Equation 4) to account for viscous strain-rate effects on soil strength, and $q_{\mathrm{D}}$ to account for drag effects, similar to that required in the indirect method. The direct method still requires selection of an appropriate value for $N_{\mathrm{kt}}$, although this aspect of the interpretation is no different from the analysis of pushin cone penetrometer test data.

Previous studies have also considered the direct method, but have applied strain rate effects to the measured cone tip resistance, $q_{\mathrm{c}}$ (Buhler \& Audibert 2012; Steiner et al. 2014). However, this approach is less accurate as it implies that the viscous strain rate dependency is also applied on the buoyancy and drag resistance. Mulukutla (2009) applied $R_{\mathrm{f} \text { (tip) }}$ to $q_{\text {net }}\left(q_{\text {net }}=q_{\mathrm{c}}+u_{2}(1-\right.$ $\left.\left.\alpha_{\text {cone }}\right)-\sigma_{\mathrm{vo}}\right)$, which neglects drag resistance and would result in an over-prediction of $s_{\mathrm{u}}$ at shallow depths, as discussed further in Section 0.

As with the indirect method, the FFP velocity (used in Equation 4) and the FFP displacement (used to establish the depth profile of strength) are determined from the FFP linear acceleration through single and double numerical integration respectively.

\section{CENTRIFUGE EXPERIMENTS}

\section{Model FFP and Instrumentation}

The FFP used in these tests was a centrifuge scale piezocone with a $60^{\circ}$ cone tip and a cone and shaft diameter of $10 \mathrm{~mm}$ (Fig. 3). It has an overall length of $120 \mathrm{~mm}$ and a mass of $29 \mathrm{~g}$. This model piezocone was used in the free-fall (dynamic) tests and also in the push-in (static) tests, attached to the static actuator. 
The model FFP has tip and sleeve load cells and a pore pressure transducer located just above the cone shoulder ( $u_{2}$ position). The filter for the pore pressure transducer was a $1.3 \mathrm{~mm}$ thick ring of polyethylene with a $35 \mu \mathrm{m}$ pore size, and an inner and outer diameter of 8 and $10 \mathrm{~mm}$ respectively. The FFP instrumentation also included a MEMS (micro-electro mechanical system) 1-axis accelerometer (O'Loughlin et al. 2014). The sensor wires were combined in a single trailing cable that exited at the top of the shaft, in a manner similar to the trailing release and retrieval line in a full scale FFP.

\section{Soil Properties and Preparation Technique}

The tests were conducted in normally-consolidated kaolin clay with properties as listed in Table 1. The soil sample was prepared following the procedure described in Chow et al. (2014) in a centrifuge strongbox measureing (internally) $650 \mathrm{~mm}$ long, $390 \mathrm{~mm}$ wide and $325 \mathrm{~mm}$ deep. The final sample height was approximately $230 \mathrm{~mm}$. A $50 \mathrm{~mm}$ water layer was maintained at the sample surface to ensure saturation.

\section{Centrifuge Test Details and Procedures}

The centrifuge tests were carried out at an acceleration of $100 \mathrm{~g}$ using the $1.8 \mathrm{~m}$ radius fixed beam Acutronic 661 centrifuge at the Centre for Offshore Foundation Systems in The University of Western Australia. Six free-fall piezocone (FFP) tests and three static piezocone tests were performed, with the parameters given in Table 2.

For ease of reference, tests are identified as $\mathrm{XnnnY}$, where $\mathrm{X}$ is either $\mathrm{S}$ for a static test or $\mathrm{D}$ for a dynamic test, nnn refers to either the penetration velocity in a static test or the impact velocity in a dynamic test (both in $\mathrm{m} / \mathrm{s}$ ) and $\mathrm{Y}$ is an alphabetic character denoting the test recurrence (a for the first test, $b$ for the second etc.) For instance, Test D1a refers to the first occurrence of a free-fall piezocone test at impact velocity, $v_{\mathrm{i}} \sim 1 \mathrm{~m} / \mathrm{s}$. 
The centrifuge test setup for both the free-fall and static piezocone tests is as described in Chow et al. (2014) and shown in Fig. 4. The model FFP was installed dynamically using a guide to prevent lateral movement during free-fall. FFP release was achieved in-flight using a resistor which, when powered, heated and subsequently burned through the release cord, triggering the drop (O'Loughlin et al. 2004) and data acquisition at 50kHz (Gaudin et al. 2009). The centrifuge was then halted and a direct measurement of the FFP embedment depth taken to provide a comparison with that derived from the accelerometer measurements. The static piezocone tests involved penetration velocities, $v=0.001,0.01$ and $0.1 \mathrm{~m} / \mathrm{s}$ (such that $v / d=$ $0.1,1$ and $\left.10 \mathrm{~s}^{-1}\right)$. In addition to penetration tests to assess strength, piezocone dissipation tests were conducted at depths typical of the embedment depths achieved in the FFP tests.

\section{Results}

Undrained shear strength profiles were first established from the push-in piezocone tests $(v / d$ $=0.1,1$ and $\left.10 \mathrm{~s}^{-1}\right)$ using the static net cone resistance, $q_{\text {net(s): }}$ :

$$
s_{u}=\frac{q_{n e t(s)}}{N_{k t}}=\frac{q_{c}+u_{2}\left(1-\alpha_{\text {cone }}\right)-\sigma_{v o}}{N_{k t}}
$$

where the cone capacity factor, $N_{\mathrm{kt}}=12$ for UWA kaolin clay as established by Chow et al. (2014) through calibration with T-bar strength profiles interpreted using $N_{\text {T-bar }}=10.5$. The interpreted $s_{\mathrm{u}}$ profiles along with the T-bar strength profiles are provided in Fig. 5. The strength profiles indicate good agreement between the static piezocone tests but with up to $\pm 20 \%$ variation from the mean strength for the T-bar tests.

An example depth profile of measured tip and shaft load cell output during a free-fall test (Test D11a) is provided in Fig. 6. The load cells were zeroed at the release height and whilst the centrifuge was spinning at $100 \mathrm{~g}$. The apparent load immediately after release reflects the weights (corresponding with the centrifuge radius and g-level at the FFP release height) of the 
parts of the FFP below the tip and sleeve load cells. They arise from the stepwise change in linear acceleration during free-fall.

A correction was applied to the tip and shaft load cell data, by an amount equal to the unregistered mass times the linear acceleration, $a$, at the current FFP location, $m_{\mathrm{c}} a$ or $m_{\mathrm{s}} a$ (where $m_{\mathrm{c}}$ and $m_{\mathrm{s}}$ are the mass of material below the tip and sleeve load cells respectively). The measured and corrected load cell profiles are shown in Fig. 6, and are zero up to impact with the mudline.

Profiles of cone tip resistance, $q_{\mathrm{c}}$ and shaft resistance, $f_{\mathrm{s}}$ for selected static and free-fall tests are provided in Fig. $7 \mathrm{a}$ and Fig. $7 \mathrm{~b}$, where $q_{\mathrm{c}}$ and $f_{\mathrm{s}}$ for the free-fall tests are simply the corrected $F_{\mathrm{c}}$ and $F_{\mathrm{s}}$ divided by the cone tip and friction sleeve area respectively. The shaft resistance, $f_{\mathrm{s}}$ remains close to zero until the penetration coincides with the friction sleeve mid-height passing the mudline (as shown in Fig. 6b). Fig. 7 shows that tip resistance, $q_{\mathrm{c}}$ and shaft resistance, $f_{\mathrm{s}}$ are much higher in the free-fall tests than in the static tests. Increasing penetration velocity causes increasing strain rates in the soil in the vicinity of the advancing FFP, which increases $q_{\mathrm{c}}$ slightly and $f_{\mathrm{s}}$ significantly. This is discussed further in Section 0.

In addition to the $q_{\mathrm{c}}$ and $f_{\mathrm{s}}$ profiles, Fig. 7 also shows the excess pore pressure, $\Delta u_{2}$ and normalised excess pore pressure with vertical effective stress, $\Delta u_{2} / \sigma_{\mathrm{v}}$ profiles with depth, $z$. The normalised excess pore pressure term, $\Delta u_{2} / \sigma_{\mathrm{v}}$ has been adopted instead of the usual pore pressure parameter, $B_{\mathrm{q}}=\Delta u_{2} / q_{\text {net. }}$ Unlike $q_{\text {net }}, \sigma_{\mathrm{v}}$ does not include rate effects, allowing the effect of strain rate on pore pressure response to be more clearly examined (Schneider et al. 2008). For the static piezocone tests, $\Delta u_{2}$ and $\Delta u_{2} / \sigma_{\mathrm{v}}$ are positive and highly repeatable. In contrast, profiles of $\Delta u_{2}$ and $\Delta u_{2} / \sigma_{\mathrm{v}}$ from the FFP tests are negative for tests with impact velocities, $v_{\mathrm{i}}>1 \mathrm{~m} / \mathrm{s}$, as also noted in FFP centrifuge experiments reported by Chow et al. (2014). This is considered to be caused by the conical tip forcing soil radially outwards at a 
high rate, such that suction is generated to retain the soil in contact with the cone shaft as it rounds the shoulder (Chow et al. 2014).

\section{UNDRAINED SHEAR STRENGTH CALCULATION}

\section{Back-analysis of strain rate effects in tip and shaft resistances}

Regardless of whether the direct or indirect approach is taken, calculation of $s \mathrm{u}$ from the FFP interpretation requires treatment of the data to account for strain rate effects. Direct measurement of both the dynamic and static tip and shaft resistance provides an opportunity for back analysing these strain rate effects.

For tip resistance, the strain rate dependency, $R \mathrm{f}(\mathrm{tip})$ has been calculated by considering the ratio $q_{\text {net(d) }} / q_{\text {net(s), }}$, where the dynamic net tip resistance, $q_{\text {net(d) }}=q_{\mathrm{c}}+u_{2}\left(1-\alpha_{\mathrm{cone}}\right)-\sigma_{\mathrm{vo}}-q_{\mathrm{D}}$ and the static net tip resistance, $q_{\mathrm{net}(\mathrm{s})}=q_{\mathrm{c}}+u_{2}\left(1-\alpha_{\mathrm{cone}}\right)-\sigma_{\mathrm{vo}}$. As described in Section $0, q_{\mathrm{net}(\mathrm{d})}$ as defined here ensures that the comparison between dynamic and static resistance data reflects changes in soil strength due solely to strain rate effects. Similarly for shaft resistance, the strain rate dependency $R_{\mathrm{f}(\text { shaft })}$ can be calculated by considering $f_{\mathrm{s}(\mathrm{d})} / f_{\mathrm{s}(\mathrm{s})}$. Ideally the shaft resistance, $f_{\mathrm{s}}$ should be corrected for the differential water pressure acting on the ends of the sleeve. However, this requires measurement of pore pressure at the top of sleeve $\left(u_{3}\right)$ position (ASTM 2012), which is rarely made. No attempt has been made to correct the friction sleeve measurements here.

Fig. 8 shows example profiles of velocity and net tip resistances, $q_{\text {net(s) }}$ and $q_{\text {net(d) }}$ with penetration depth from the static and free-fall piezocone tests. The three static piezocone tests with $v / d=0.1,1$ and $10 \mathrm{~s}^{-1}$, were considered as the basis for selecting the reference static net resistance, $q_{\text {net(s). }}$ With the range of FFP impact velocities between 1 and $10 \mathrm{~m} / \mathrm{s}(v / d=100$ to $1000 \mathrm{~s}^{-1}$ ), the three static piezocone with $v / d=0.1$ to 10 represent a difference of 3 to 5 order of magnitude from the FFP tests. As the three static piezocone tests present very similar $q_{\text {net(s) }}$ 
profiles (Fig. 9a), a $q_{\text {net(s) }}$ profile averaged from the three tests is used to compute $R_{\mathrm{f}(\text { tip) }}$ for all FFP tests as shown in Fig. 9b. As the reference normalised velocity increases from $v / d=0.1$ to 10, the better the power-law rate formula fits the FFP test data. Hence $v / d=10$ (Test S0.1a) is selected as the reference normalised velocity for computing $R_{\mathrm{f}(\mathrm{tip})}$ for all FFP tests. For consistency, $R_{\mathrm{f}(\mathrm{shaft})}$ was also computed using the same reference normalised velocity of $v / d$ $=10$.

Using Test S0.1a as the reference case, the variation in rate effects for tip and shaft resistances,

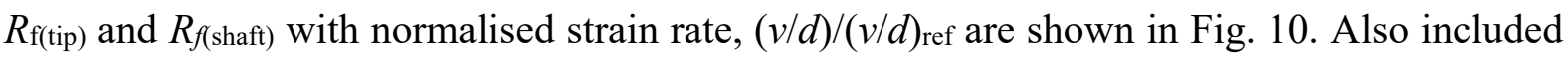
in Fig. 10 is the formulated $R_{\mathrm{f}(\mathrm{tip})}$ and $R_{f(\text { shaft) }}$ using the power law (Equations 4 and 5) adopting a range of rate parameters. $R_{\mathrm{f}(\mathrm{tip})}$ is bracketed by $\beta_{\text {tip }}=0.035$ and 0.085 , which are typical of values cited in the literature and the value of 0.06 gives a good fit. In contrast, the shaft resistance data are bracketed by $\beta_{\text {shaft }}=0.18$ to 0.24 , with the best agreement obtained using $\beta_{\text {shaft }}=0.21$. These higher values of $\beta$ are consistent with laboratory and field observations by others (Dayal et al. 1975, Steiner et al. 2014) and indicate that the dynamic enhancement of the frictional resistance can be much greater than can be attributed only to the effect of strain rate on soil strength. $\beta_{\text {shaft }}=0.21$ is significantly greater than observed via other types of high strain rate element testing of kaolin (e.g. Boukpeti et al. 2009). It is therefore likely that the true mechanism behind the much higher dynamic frictional resistance is caused by additional effects. One example is the inertial forces involved as the soil is pushed rapidly outwards during flow around the tip, while then remaining adhered to the shaft during further penetration.

To quantify the resulting relative strength of the rate effects on the penetration resistance at the tip and the shaft, the measured $R_{\mathrm{f}(\mathrm{tip})}$ and $R_{f(\text { shaft }}$ at a penetration depth, $z=6 \mathrm{~m}$ are presented in Table 3. $R_{\mathrm{f}(\mathrm{tip})}$ ranges between 1.40 and 1.67 and $R_{f(\text { shaft })}$ ranges between 2.09 and 2.51 , such that $R_{f(\text { shaft }} / R_{\mathrm{f}(\mathrm{tip})}=1.31-1.79$. This much higher $R_{f(\text { shaft })}$ presents a difficulty in quantifying the 
dynamic shaft resistance, and consequently in calculating $s_{\mathrm{u}}$ using the accelerometer method, as will be demonstrated later.

\section{Tip load cell method}

Using the approach described in Section 0, the undrained shear strength, $s_{\mathrm{u}}$ has been calculated for all FFP tests using the best-fitted rate parameter, $\beta_{\text {tip }}=0.06$ as shown in Fig. 11a. Good agreement is obtained between $s$ u back calculated from the FFP tests with the reference $s u$ profiles obtained from piezocone test S0.1a.

In addition, despite registering suction during FFP penetration, the unequal area correction applying the $u_{2}$ (suction) data leads to reliable calculations of $s_{u}\left(u_{2}(1-\alpha)\right.$ ranging typically from $5-20 \%$ of the cone tip resistance $q_{\mathrm{c}}$ ). On average the FFP-derived $s$ u profiles are within $\pm 10 \%$ of the static piezocone and T-bar test results.

It is also important to consider drag resistance as discussed in Section 0. The consequence of ignoring drag is illustrated in Fig. 11b, in which $s_{\mathrm{u}}$ is over-predicted by up to $50 \%$ at shallow depths. The magnitude of the over-prediction reflects the increase in drag resistance with increasing impact velocity (Equation 6).

It is useful to examine the influence of rate parameter, $\beta_{\text {tip }}$ on the accuracy of the tip load cell method, given that this parameter must be assumed in the analysis. Typical lower bound, mean and upper bound values of $\beta$ are $0.035,0.06$ and 0.085 based on the literature for soil element behaviour (e.g. Boukpeti et al. 2009), and these show good agreement with the back-calculated rate parameter, $R_{\mathrm{f}(\mathrm{tip})}$ as shown in Fig. 10. The resulting $s_{\mathrm{u}}$ profiles for this range of $\beta_{\text {tip }}$ are presented in Fig. 12. The lower and upper bound values of $\beta_{\text {tip }}=0.035$ and 0.085 produce $s_{\mathrm{u}}$ profiles that fall within $\pm 15 \%$ of that produced using $\beta_{\text {tip }}=0.06$.

For an FFP with a tip load cell but no $u_{2}$ measurement, it would be useful to predict the $u_{2}$ necessary for the unequal area correction that would apply for most arrangements of tip load 
cell (even when a pore pressure transducer is not present at the $u_{2}$ position). A potential approach to establish the $u_{2}$ values is by back-analysing the pore pressure parameter, $B_{\mathrm{q}}=\left(u_{2}\right.$ $\left.u_{\mathrm{w}}\right) / q_{\text {net }}$ from the centrifuge test data, to identify when $B_{q}$ (and hence $u_{2}$ ) can be predicted as a function of penetration velocity.

The $B_{\mathrm{q}}$ profiles for all static and FFP tests are illustrated in Fig. 13a and the relationships between $B_{\mathrm{q}}$ with the penetration velocity are examined in Fig. 13b. For static piezocone tests, a range of $B_{\mathrm{q}}$ is observed within each single test with constant penetration velocity. On the contrary, the FFP tests appear to produce $B_{\mathrm{q}}$ profiles that, although are less variable with penetration depth and hence velocity, still demonstrate some dependence on impact velocity. This suggests that different mechanisms are operatively controlling the $B_{q}$ response at different speeds - which is consistent with the hypothesis that other mechanisms beyond only the strain rate effect on soil strength - are leading to the high value of $\beta_{\text {shaft }}$ observed in the dynamic tests (see Section 0). The observed $B_{\mathrm{q}^{-}} v$ and $B_{\mathrm{q}^{-}} z$ dependence within the dynamic results is also likely to be affected by soil type and state so a different trend would be expected beyond the normallyconsolidated kaolin tested in this study.

Hence it appears necessary to include $u_{2}$ measurement, and to ensure proper saturation of the pore pressure filter and the fluid channels between the filter and the sensor, in any FFP design in order to reliably interpret $s$ u using the tip load cell method. This conclusion is consistent with static CPT protocols, in which a correction using the measured $u_{2}$ pore pressure is a standard part of any $s_{u}$ determination from the cone tip resistance.

\section{Accelerometer method}

The undrained shear strength, $s u$ was also calculated for all FFP tests using the accelerometer method described in Section 0. The method involves solving the governing equation (Equation 1), and also accounts for additional resistance generated as friction between the FFP and the 
installation guide. The magnitude of the frictional resistance was quantified from the acceleration measurements at impact with the soil when the FFP was fully within the guide, and was assumed to diminish linearly as the length of FFP in the guide reduced to zero. As discussed in Section 0, Equation 1 also requires an assumption regarding the soil in the wake of the FFP should it become fully buried in the soil (as was the case for the tests considered here). In the present calculations, the hole formed by the passage of the FFP was assumed to remain open over the time taken for dynamic installation, such that no additional bearing resistance at the rear of the FFP was included (O'Loughlin et al. 2013).

Using the parameters listed in Table 4 , the calculations were first made using values of $\beta_{\text {tip }}=$ 0.06 and $\beta_{\text {shaft }}=0.21$ established from the tip and load cell measurements (Approach 1). The resulting $s_{u}$ profiles are shown in Fig. $14 \mathrm{a}$, where it is apparent that whilst the FFP $s_{u}$ profiles bracket the reference $s_{u}$ profile from the push-in test, the variation is higher and is weighted towards over-predicting the strength, typically by $50 \%$. This disparity is surprising, as the predictions were obtained using the rate parameters derived from the load cell measurements, with separate parameters for tip and shaft. However, the interface friction ratio for the shaft was taken 'blind' as $\alpha=1 / S_{\mathrm{t}}=0.4$ (based on kaolin sensitivity derived from cyclic T-bar tests of 2.5).

It follows that the inaccuracy will be even higher in field applications where these strain rate parameters, in addition to the interface friction ratio, would need to be selected a priori. This type of 'blind' calculation is illustrated in Fig. 14b, which shows the results of a second calculation (Approach 2) made using $\beta_{\text {tip }}=\beta_{\text {shaft }}=0.06$ (which are typical values reported in the literature for soil element behaviour and free-fall penetration problems in clay). The resulting $s u$ profiles are compared with the reference $s u$ profile on Fig. 14b. As expected, the over-prediction is (in most cases) even higher as this parameter set leads to a lower calculated 


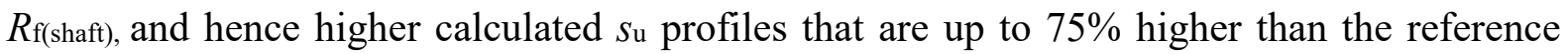
profile.

The accelerometer method clearly produces much poorer predictions of $s u$ than the tip load cell method. This is attributed to shortcomings in predicting the shaft resistance accurately using Equation 3. For this type of FFP, which embeds by up to $z / D=10$, the shaft resistance is of comparable magnitude to the tip resistance at the final depth. Therefore, the 'correction' of removing the shaft resistance is often equal to the tip resistance. This means that errors in the assumed interface friction ratio or rate correction lead to proportional errors in the calculated Su.

As illustrated in Fig. 15a, back analysis of the measured static friction sleeve resistance (i.e. from a push-in piezocone test with $v=0.1 \mathrm{~m} / \mathrm{s}$ ), required $\alpha=0.6$, which is higher than $\alpha=0.4$, as assumed in Approach 1 and 2 (based on the inverse of the sensitivity). Extending this knowledge of $\alpha$ to the dynamic shaft resistance, it is clear from Fig. 15b that using the higher $\alpha=0.6$, together with the back-figured $\beta_{\text {shaft }}=0.21$ leads to accurate prediction of the dynamic friction sleeve resistance. Fig. 16a shows that adopting this improvement results in better predictions of $s u$, but only to about $z=8 \mathrm{~m}$, beyond which the predicted $s$ uprofiles are lower than that established from the push-in test. Interestingly Fig. 16b shows (for test D6) that the use of either the formulated or measured dynamic resistance (extrapolated beyond the instrumented section to represent the expected dynamic resistance over the full shaft length) provides equivalent $s$ u profiles, with the same under-prediction of $s$ u beyond $z=8 \mathrm{~m}$, This implies that the assumption of linear variation in shaft resistance with depth is only valid to a particular depth, beyond which the mobilised dynamic friction resistance is reduced. This may be due to eventual water entrainment at the shaft-soil interface, or some other effect that would require either a different interface friction ratio or strain rate quantification with depth. Such 
complexities are difficult to implement, and support the use of the simpler and more reliable tip-load cell method.

The relatively poor level of agreement obtained between push-in and dynamic $s u$ profiles on Fig. 14 points to the difficulties in applying the accelerometer method. Although Fig. 16 shows that better agreement may be obtained when the uncertainty on the dynamic shaft resistance is reduced, Fig. 14b is more reflective of the (poorer) level of agreement that would be obtained when the dynamic shaft resistance needs to be estimated 'blind', as would be the case for field applications where prior information on the shaft resistance parameters is either unavailable or limited.

\section{CONCLUSIONS}

This study has extended existing methods for interpreting FFP measurements to determine the undrained shear strength, $s_{\mathrm{u}}$. A new tip load cell $s_{\mathrm{u}}$ interpretation method (Equation 10) has been outlined, which considers the contribution of drag resistance and ensures that strain rate effects are applied only to the soil strength component of resistance. The method was applied to centrifuge tests in kaolin clay and was seen to provide profiles of undrained shear strength, $s_{u}$ that were in excellent agreement with those derived from push-in piezocone tests, and indeed exhibited less variability than repeat push-in piezocone tests. Varying the strain rate parameter for the tip from $\beta_{\text {tip }}=0.035$ to 0.085 resulted in only $\pm 15 \%$ variation in the calculated undrained shear strength.

Comparisons of static and dynamic tip and shaft resistance measurements revealed that the tip exhibits strain rate dependency of about $14 \%$ per decade variation in strain rate $\left(\beta_{\text {tip }}=0.06\right)$, consistent with the bulk of the literature. In contrast the shaft measurements indicate much higher strain rate dependency - almost $48 \%$ per decade variation in strain rate $\left(\beta_{\text {shaft }}=0.21\right)-$ higher than is typically allowed for. However, even when this known dependence of soil 
strength on strain rate was accounted for, it became difficult to obtain accurate profiles of undrained shear strength, $s_{\mathrm{u}}$ using the indirect accelerometer method (Equation 1). The inaccuracy in FFP $s$ u profiles obtained using the accelerometer method reflects the difficulty in reliably quantifying the dynamic shaft resistance, an aspect of the problem that is removed when using the direct tip load cell method. Problems associated with using the accelerometer method become exacerbated when applied to new sites, for which limited or no information on the interface friction ratio or shaft strain rate dependency may be available.

From this study, indicative uncertainties for the various methods of detecting $q_{\mathrm{c}}$ can be derived, as summarised in Table 5. These uncertainties are relevant to a free-fall piezocone reaching a final embedment of $z / D \sim 10$ in soft clay. They are in addition to other uncertainties always present in cone resistance measurements, which are discussed in detail by Peuchen \& Terwindt (2010). The comparison with static CPT resistance uncertainty provides context for the additional uncertainty created by the use of free-fall devices.

In summary, this paper has demonstrated that for slender free-fall penetrometers such as the free-fall cone penetrometer considered here, the tip load cell method is much more accurate for quantifying $s_{\mathrm{u}}$ than the accelerometer method and can produce $s_{\mathrm{u}}$ profiles that are within $\pm 10 \%$ of those obtained from push-in piezocone tests. This accuracy is only achieved when reliable pore pressure data at the cone shoulder ( $u_{2}$ position) are also gathered to allow correction of the tip load. In contrast, for the present data set, the accelerometer method yields uncertainty of up to $75 \%$, due to uncertainties associated with predicting the shaft resistance.

\section{Acknowledgements}

This work forms part of the activities of the Centre for Offshore Foundation Systems (COFS), currently supported as a node of the Australian Research Council's Centre of Excellence for Geotechnical Science and Engineering, and through the Fugro Chair in Geotechnics (held by 
the fourth author), the Lloyd's Register Foundation Chair and Centre of Excellence in Offshore Foundations and the Shell EMI Chair in Offshore Engineering (held by the third author).

The work is funded by UWA's ECM research development grant (P10300069) and the Remote Intelligent Geotechnical Seabed Surveys (RIGSS) Joint Industry Project, which is support by Benthic Geotech, Fugro, Shell, Total and Woodside.

\section{References}

ASTM (2012). ASTM D5778 Standard test method for performing electronic friction cone and piezocone penetration testing of soils.

Beard, R.M. (1981). A penetrometer for deep ocean seafloor exploration. In OCEANS 1981, The ocean: an international workplace (Vol. 13, pp. 668-673). Boston, MA, United States.

Biscontin, G. \& Pestana, J.M. (2001) Influence of peripheral velocity on vane shear strength of an artificial clay. Geotechnical Testing Journal 24, No. 4, 423-429.

Blake, A.P. \& O'Loughlin, C.D. (2015) Installation of dynamically embedded plate anchors as assessed through field tests. Canadian Geotechnical Journal 52, No. 9, 1270-1282.

Blake, A.P., O’Loughlin, C.D., Morton, J.P, O’Beirne, C., Gaudin, C. \& White, D.J. (2016) Insitu measurement of the dynamic penetration of free-fall projectiles in soft soils using a low cost inertial measurement unit. ASTM Geotechnical Testing Journal 39, No. 2, 235251.

Boukpeti, N., White, D. J., Randolph, M. F., \& Low, H. E. (2012). Strength of fine-grained soils at the solid-fluid transition. Geotechnique 62, No. 3, 213-226.

Buhler, R.L. \& Audibert, J.M.E. (2012). Rate-effect correction methods for free-fall cpt data in deepwater gulf of mexico - an operator's perspective. In 7th International Offshore Site Investigation \& Geotechnics Conference, 'Integrated Geotechnologies - Present \& Future'. London, UK: Society for Underwater Technology.

Chow, S. \& Airey, D. (2013). Soil strength characterisation using free-falling penetrometers. Geotechnique 63, No. 13, 1131-1143.

Chow, S. \& Airey, D. (2014). Free-Falling Penetrometers: A Laboratory Investigation in Clay. Journal of Geotechnical and Geoenvironmental Engineering 140, No. 1, 201-214.

Chow, S.H., O'Loughlin, C.D. \& Randolph, M.F. (2014). Soil strength estimation and pore pressure dissipation for free-fall piezocones in soft clay. Geotechnique 64, No. 10, 817 827.

Dayal, U., Allen, J. \& Jones, J. (1975). Use of an impact penetrometer for the evaluation of the in-situ strength of marine sediments. Marine Georesources \& Geotechnology 1, No. 2, $73-$ 89.

Einav, I., \& Randolph, M. F. (2006). Effect of strain rate on mobilised strength and thickness of curved shear bands. Geotechnique 56, No. 7, 501-504. 
Gaudin, C., White, D. J., Boylan, N., Breen, J., Brown, T., De Catania, S., \& Hortin, P. (2009). A wireless high-speed data acquisition system for geotechnical centrifuge model testing. Measurement Science and Technology 2, No. 9, 095709.

Lehane, B.M., O’Loughlin, C.D., Gaudin, C., \& Randolph, M.F. (2009). Rate effects on penetrometer resistance in kaolin. Geotechnique 59, No. 1, 41-52.

Morton, J., O'Loughlin, C.D. \& White, D. (2015). Estimation of soil strength by instrumented free-fall sphere tests. Géotechnique, accepted.

Mulukutla, G.K. (2009). Determination of geotechnical properties of seafloor sediment. $\mathrm{PhD}$ thesis, University of New Hampshire, USA.

O'Loughlin, C.D., Randolph, M.F. and Richardson, M. (2004). Experimental and theoretical studies of Deep Penetrating Anchors. Proceedings of the 2004 Offshore Technology Conference, Paper No. OTC16841.

O'Loughlin, C.D., Richardson, M.D. and Randolph, M.F. (2009). Centrifuge tests on dynamically installed anchors. Proceedings of the 28th International Conference on Ocean, Offshore and Arctic Engineering, Honolulu, Hawaii, Paper No. OMAE2009-80238, 391399.

O'Loughlin, C.D., Richardson, M.D., Randolph, M.F. \& Caudin, C. (2013) Penetration of dynamically installed anchors in clay. Géotechnique 63, No. 11, 909-919.

O'Loughlin, C.D., Gaudin, C., Morton, J.P. and White, D.J. (2014). The use of Micro-Electro Mechanical System accelerometers for measuring dynamic penetration events in geotechnical centrifuge tests. The International Journal of Physical Modelling in Geotechnics 14, No. 2, 31-39.

Randolph, M.F. \& Hope, S. (2004). Effect of cone velocity on cone resistance and excess pore pressures. In Proceedings of the international symposium on deformation characteristics of geo- materials - IS Osaka, pp. 147-152. Tokyo, Japan: Japanese Geotechnical Society.

Randolph, M. F. \& White, D. J. (2012). Interaction forces between pipelines and submarine slides: a geotechnical viewpoint. Ocean Engineering 48, July, 32-37.

Sabetamal, H., Carter, J.P., Nazem, M. \& Sloan, S.W. (2016). Coupled analysis of dynamically penetrating anchors. Computers and Geotechnics 77, 26-44.

Sahdi, F., Gaudin, C., White, D. J., Boylan, N. \& Randolph, M.F. (2014). Centrifuge modelling of active slide-pipeline loading in soft clay. Geotechnique 64, No. 1, 16-27.

Schneider, J.A., Randolph, M.F., Mayne, P.W. \& Ramsey, N.R. (2008). Analysis of factors influencing soil classification using normalized piezocone tip resistance and pore pressure parameters. Journal of Geotechnical and Geoenvironmental Engineering 134, No. 11, $1569-1586$.

Shelton, J., Nie, C., \& Shuler, D. (2011). Installation Penetration of Gravity Installed Plate Anchors-Laboratory Study Results and Field History Data. In OTC Brazil, 1-9.

Steiner, A., Kopf, A. J., L’Heureux, J.-S., Kreiter, S., Stegmann, S., Haflidason, H. \& Moerz, T. (2014). In situ dynamic piezocone penetrometer tests in natural clayey soils-a reappraisal of strain-rate corrections. Canadian Geotechnical Journal 51, 272-288.

Peuchen, J. and Terwindt, J. (2014). Keynote paper: Introduction to CPT accuracy. 3rd Int. Symp. on Cone Penetration Testing (CPT 2014), Las Vegas, Nevada, USA. 
Raie, M. S. and Tassoulas, J. L. (2009). Installation of Torpedo Anchors: Numerical Modeling. Journal of Geotechnical and Geoenvironmental Engineering 135, No. 12, 1805-1813.

Young, A. G., Bernard, B. B., Remmes, B. D., Babb, L. \& Brooks, J. M. (2011). CPT Stinger - an innovative method to obtain CPT data for integrated geoscience studies. In Offshore Technology Conference. Houston, Texas, United states, pp. 1-10.

Zakeri, A., Hoeg, K. and Nadim, F. (2008). Submarine debris flow impact on pipelines Part I: Experimental investigation. Coastal Engineering 55, No. 12, 1209-1218.

Zhu, H. and Randolph, M. F. (2011). Numerical analysis of a cylinder moving through ratedependent undrained soil. Ocean Engineering 38, No. 7, 943-953. 


\section{List of Tables}

Table 1: Properties of UWA kaolin

Table 2: Centrifuge test program and results

Table 3: Measured $R_{\mathrm{f}(\mathrm{tip})}$ and $R_{f}($ (shaft) at depth, $z=6 \mathrm{~m}$

Table 4: Two different approaches adopted in calculating $s_{\mathrm{u}}$ using the accelerometer method: Approach 1 using measured strain rate parameters for shaft resistance, and Approach 2 using estimated strain rate parameters

Table 5: Summary of indicative uncertainties present in static and free-fall CPT results 


\section{List of Figures}

Fig. 1: (a) Forces acting on a FFP penetrating into clay; (b) estimation of soil parameters using two possible FFP instrumentation schemes

Fig. 2: Forces acting on the tip load cell of a FFP

Fig. 3: Model FFP with adaptor for static penetration tests

Fig. 4: Static penetrometer and FFP test setup in the centrifuge

Fig. 5: Undrained shear strength profiles obtained from T-bar tests $(v=0.001 \mathrm{~m} / \mathrm{s})$ and static piezocone tests $(v=0.001,0.01$ and $0.1 \mathrm{~m} / \mathrm{s})$

Fig. 6: Measured and corrected (a) tip load cell; and (b) shaft load cell data for Test D11a

Fig. 7: (a) Cone resistance; (b) shaft resistance; (c) excess pore pressure; (d) normalised excess pore pressure profiles during penetration of static and free-fall piezocone

Fig. 8: (a) Velocity profiles for FFP tests; (b) cone net tip resistance profiles for piezocone and FFP tests

Fig. 9: (a) Average static net tip resistance profile computed from Tests S0.001a, S0.01a and S0.1a; (b) Back-calculated $R$ f(tip) using the average static net tip resistance

Fig. 10: Back-fitted rate parameters for (a) net tip resistance; and (b) shaft resistance using Test S0.1 a as reference

Fig. 11: Calculated $s_{u}$ profiles using tip load cell method $\left(\beta_{\text {tip }}=0.06\right)($ a) with correction for drag; (b) without correction for drag

Fig. 12: Influence of rate parameter, $\beta_{\text {tip }}$ on the calculated $s_{\text {u }}$ profiles using the tip load cell method: (a) $\beta_{\text {tip }}=0.035$; (b) $\beta_{\text {tip }}=0.06$; and (c) $\beta_{\text {tip }}=0.085$

Fig. 13: Variation of $B_{\mathrm{q}}$ with: (a) depth, and (b) velocity

Fig. 14: FPP su profiles derived using the accelerometer method adopting: (a) Approach 1; (b) Approach 2;

Fig. 15: Formulated and measured sleeve resistance, $F_{\mathrm{s}}$ : (a) static case (Test S0.1b); (b) dynamic case (Test D6a)

Fig. 16: Demonstrated improvements in calculated FPP $s_{\mathrm{u}}$ profiles using the accelerometer method using: (a) back-analysed $\alpha=0.6$; (b) direct measurement of dynamic shaft resistance (i.e. from shaft load cell) for test D6a 
Table 1: Properties of UWA kaolin

\begin{tabular}{|l|l|}
\hline Liquid limit, LL & $61 \%$ \\
\hline Plastic limit, PL & $27 \%$ \\
\hline Specific gravity, $G_{s}$ & 2.60 \\
\hline Angle of internal friction, $\phi^{\prime}$ & $23^{\circ}$ \\
\hline Critical state frictional constant, $M$ & 0.92 \\
\hline Void ratio at $p^{\prime}=1 \mathrm{kPa}$ on critical state line, $\Gamma$ & 2.14 \\
\hline Slope of normal consolidation line, $\lambda$ & 0.205 \\
\hline Slope of swelling line, $\kappa$ & 0.044 \\
\hline
\end{tabular}


Table 2: Centrifuge test program and results

\begin{tabular}{|l|l|l|}
\hline Test ID & $\begin{array}{l}\text { Penetration rate or } \\
\text { impact velocity }(\mathbf{m} / \mathbf{s})\end{array}$ & $\begin{array}{l}\text { Prototype final } \\
\text { embedment depth (m) }\end{array}$ \\
\hline S0.001a & 0.001 & 19.3 \\
\hline S0.01a & 0.01 & 12.9 \\
\hline S0.1a & 0.1 & 12.8 \\
\hline D1a & 0.57 & 12.5 \\
\hline D1b & 0.67 & 11.65 \\
\hline D4a & 4.39 & 13.07 \\
\hline D4b & 3.73 & 12.98 \\
\hline D6a & 5.53 & 13.57 \\
\hline D11a & 10.43 & 14.92 \\
\hline
\end{tabular}

Note:

Prototype final embedment depth is the depth measured to the tip of FFP 
Table 3: Measured $R_{\mathrm{f}(\mathrm{tip})}$ and $R_{f(\text { shaft })}$ at depth, $z=6 \mathrm{~m}$

\begin{tabular}{|c|c|c|c|}
\hline Test & Velocity, $\boldsymbol{v}$ at $\mathbf{z}=\mathbf{6 ~} \mathbf{~ m ~ ( m / s )}$ & $\boldsymbol{R}_{\mathbf{f}(\text { tip })}$ & $\boldsymbol{R}_{\mathbf{f}(\text { shaft })}$ \\
\hline S0.1a & 0.1 & 1 & 1 \\
\hline D1a & 7.15 & 1.59 & 2.09 \\
\hline D4b & 7.99 & 1.50 & 2.13 \\
\hline D6a & 8.83 & 1.40 & 2.51 \\
\hline D11a & 11.87 & 1.67 & 2.43 \\
\hline
\end{tabular}


Table 4: Two different approaches adopted in calculating $s_{\mathrm{u}}$ using the accelerometer method: Approach 1 using measured strain rate parameters for shaft resistance, and Approach 2 using estimated strain rate parameters

\begin{tabular}{|l|c|c|}
\hline \multicolumn{1}{|c|}{ Parameter } & Approach 1 & Approach 2 \\
\hline Cone resistance factor, $N_{\mathrm{kt}}$ & 12 & 12 \\
\hline $\begin{array}{l}\text { Interface friction ratio, } \alpha \\
\left.\text { (assumed to be the inverse of sensitivity, } 1 / S_{\mathrm{t}}\right)\end{array}$ & 0.4 & 0.4 \\
\hline Rate parameter for tip resistance & $\beta_{\text {tip }}=0.06$ & $\beta_{\text {tip }}=0.06$ \\
\hline Rate parameter for shaft resistance & $\beta_{\text {shaft }}=0.21$ & $\beta_{\text {shaft }}=0.06$ \\
\hline Drag coefficient, $C_{\mathrm{D}}$ & 0.22 & 0.22 \\
\hline
\end{tabular}


Table 5: Summary of indicative uncertainties present in static and free-fall CPT results

\begin{tabular}{|l|l|}
\hline Case & Uncertainty in $\boldsymbol{q}_{\mathbf{c}}$ and $\mathbf{s}_{\mathbf{u}}$ \\
\hline Reference: static CPT & $\begin{array}{l}\sim \pm 5 \%{ }^{1} \\
\text { (this uncertainty is also present in FFP } q_{\mathrm{c}} \text { ) }\end{array}$ \\
\hline FFP with tip load cell & $\begin{array}{l}\text { Average error of } \sim \pm 10 \% \text { when compared } \\
\text { to static case }\end{array}$ \\
\hline $\begin{array}{l}\text { FFP using accelerometer method } \\
\text { ('blind' estimate of rate parameters } \\
\text { and shaft resistance) }\end{array}$ & $\begin{array}{l}\text { Average error up to } 75 \% \text { over prediction } \\
\text { when compared to static case }\end{array}$ \\
\hline
\end{tabular}

\footnotetext{
${ }^{1}$ based on Peuchen \& Terwindt (2010), Figure 18a
} 
(a) water surface

$\nabla$

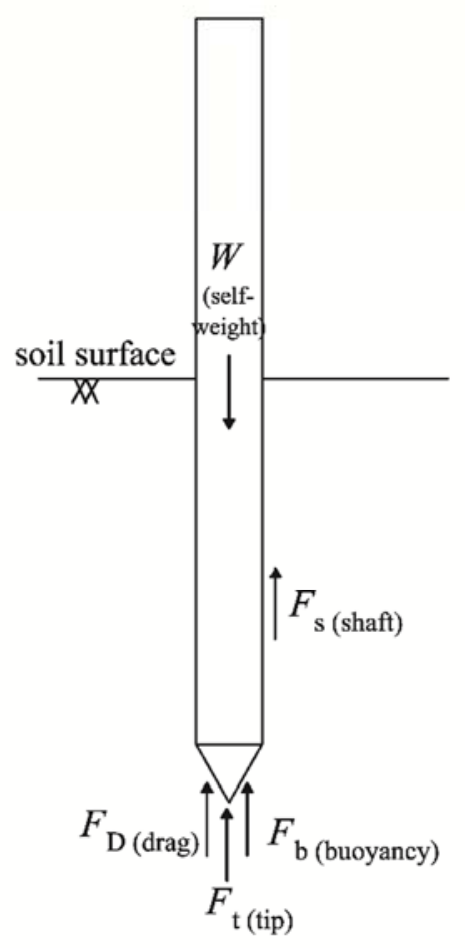

(b) water surface

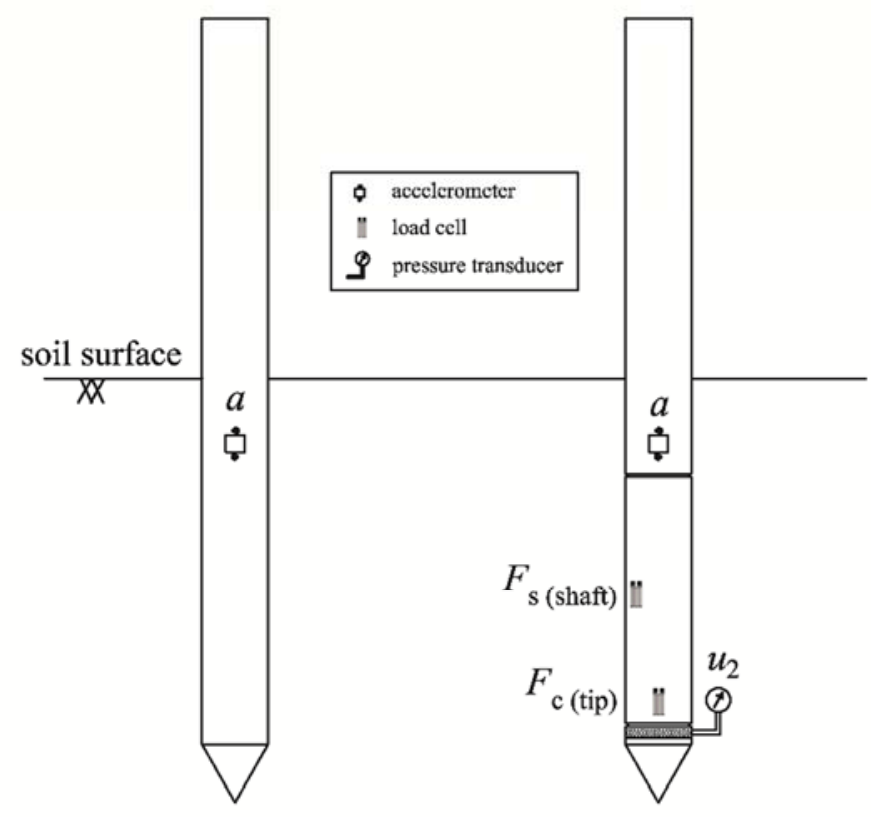

Accelerometer method

Tip load cell method

Fig. 1: (a) Forces acting on a FFP penetrating into clay; (b) estimation of soil parameters using two possible FFP instrumentation schemes 


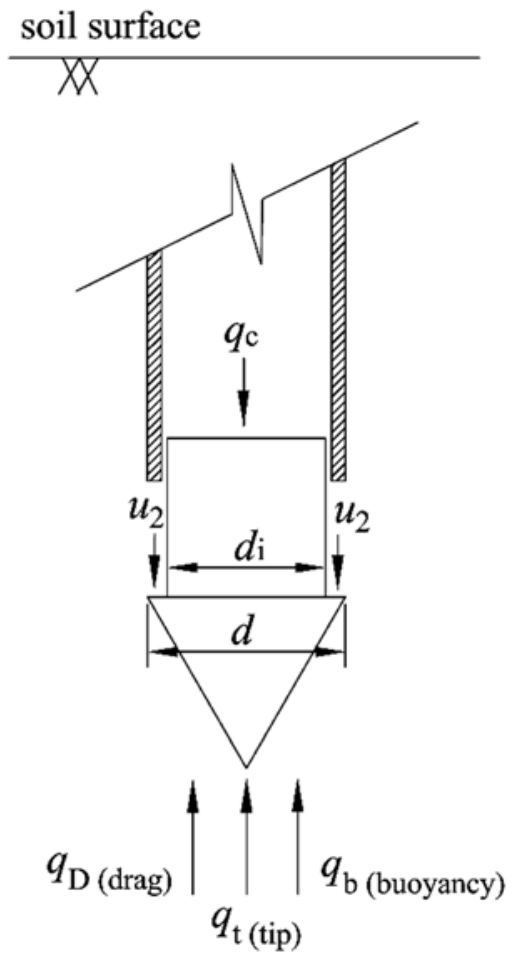

Fig. 2: Forces acting on the tip load cell of a FFP 


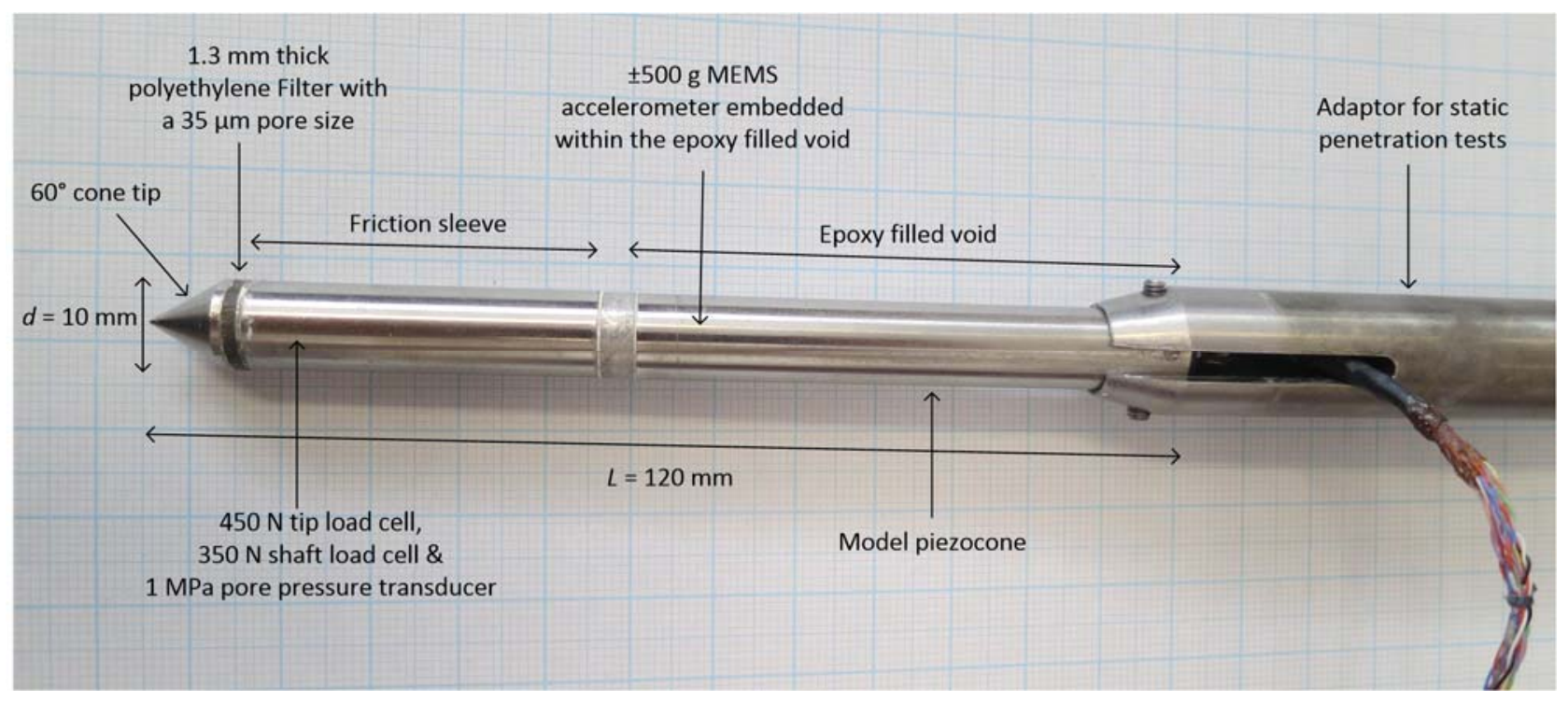

Fig. 3: Model FFP with adaptor for static penetration tests 


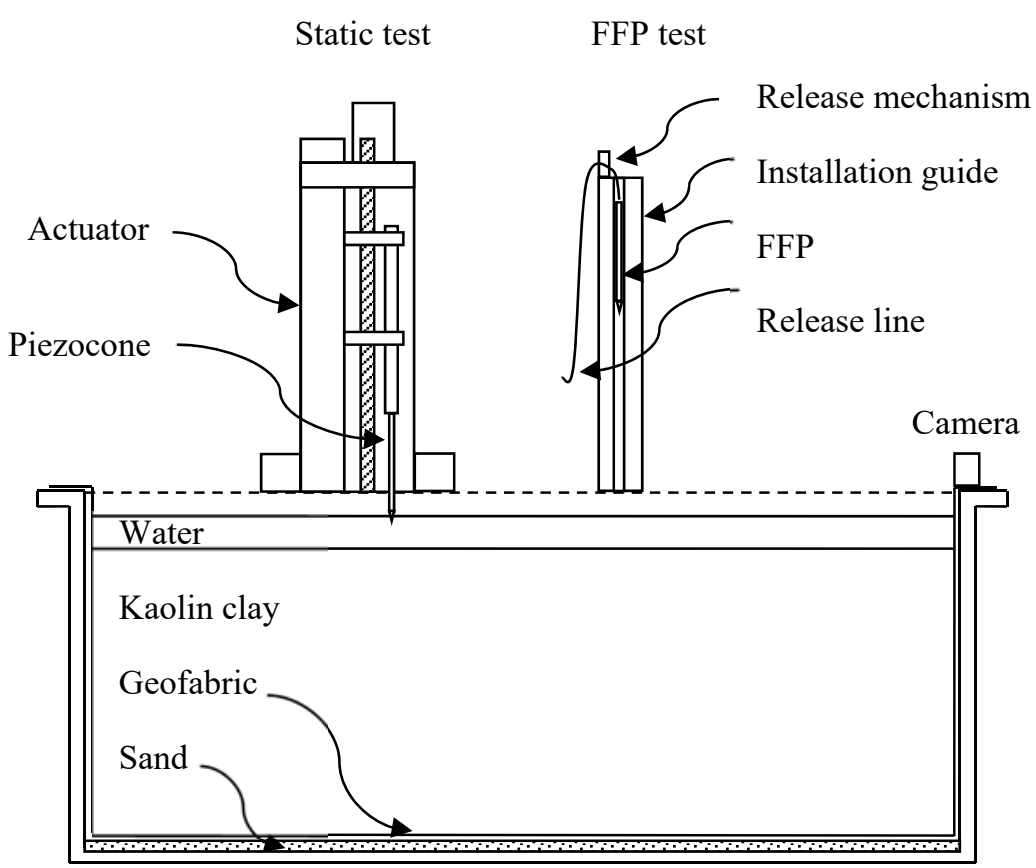

Fig. 4: Static penetrometer and FFP test setup in the centrifuge 


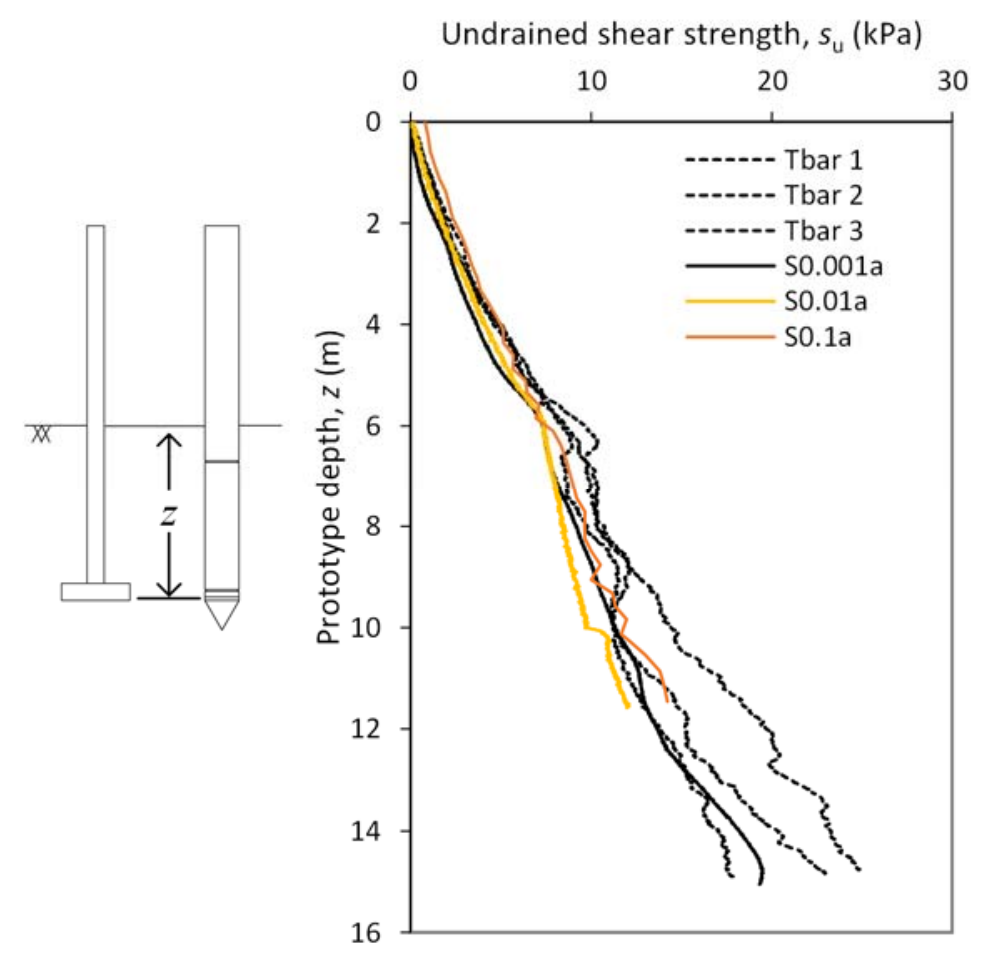

Fig. 5: Undrained shear strength profiles obtained from T-bar tests $(v=0.001 \mathrm{~m} / \mathrm{s})$ and static piezocone tests $(v=0.001,0.01$ and $0.1 \mathrm{~m} / \mathrm{s})$ 
(a)

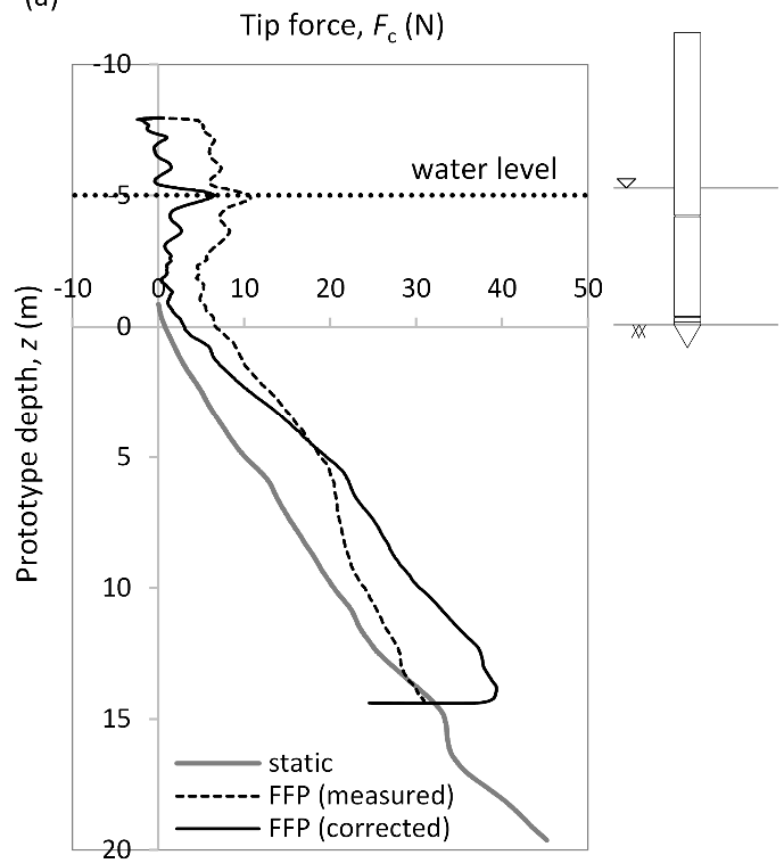

(b)

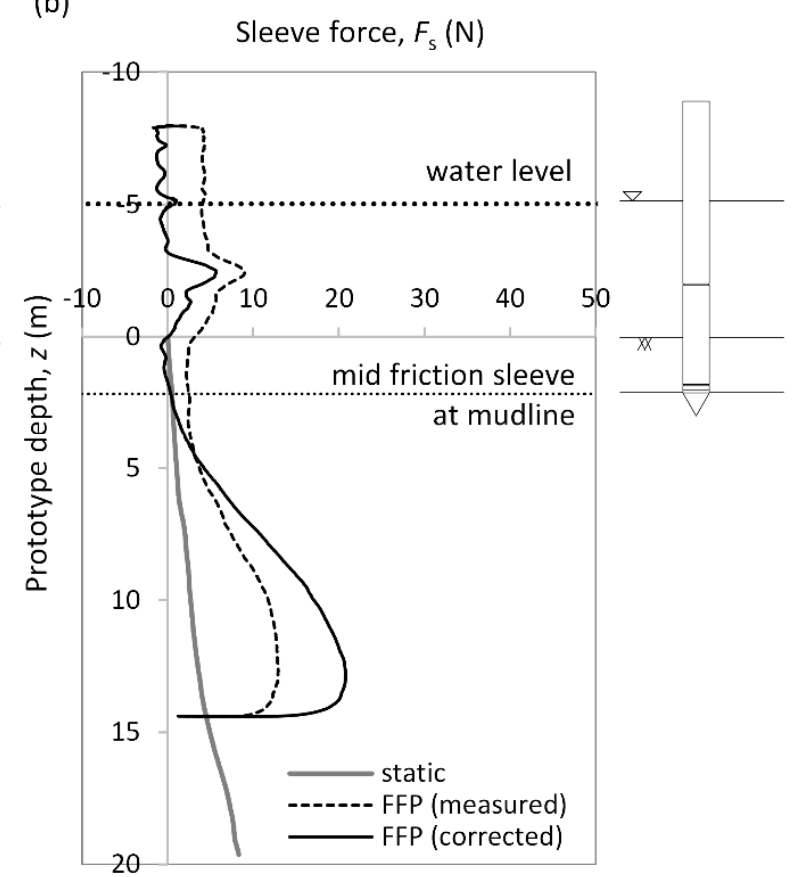

Fig. 6: Measured and corrected (a) tip load cell; and (b) shaft load cell data for Test D11a 

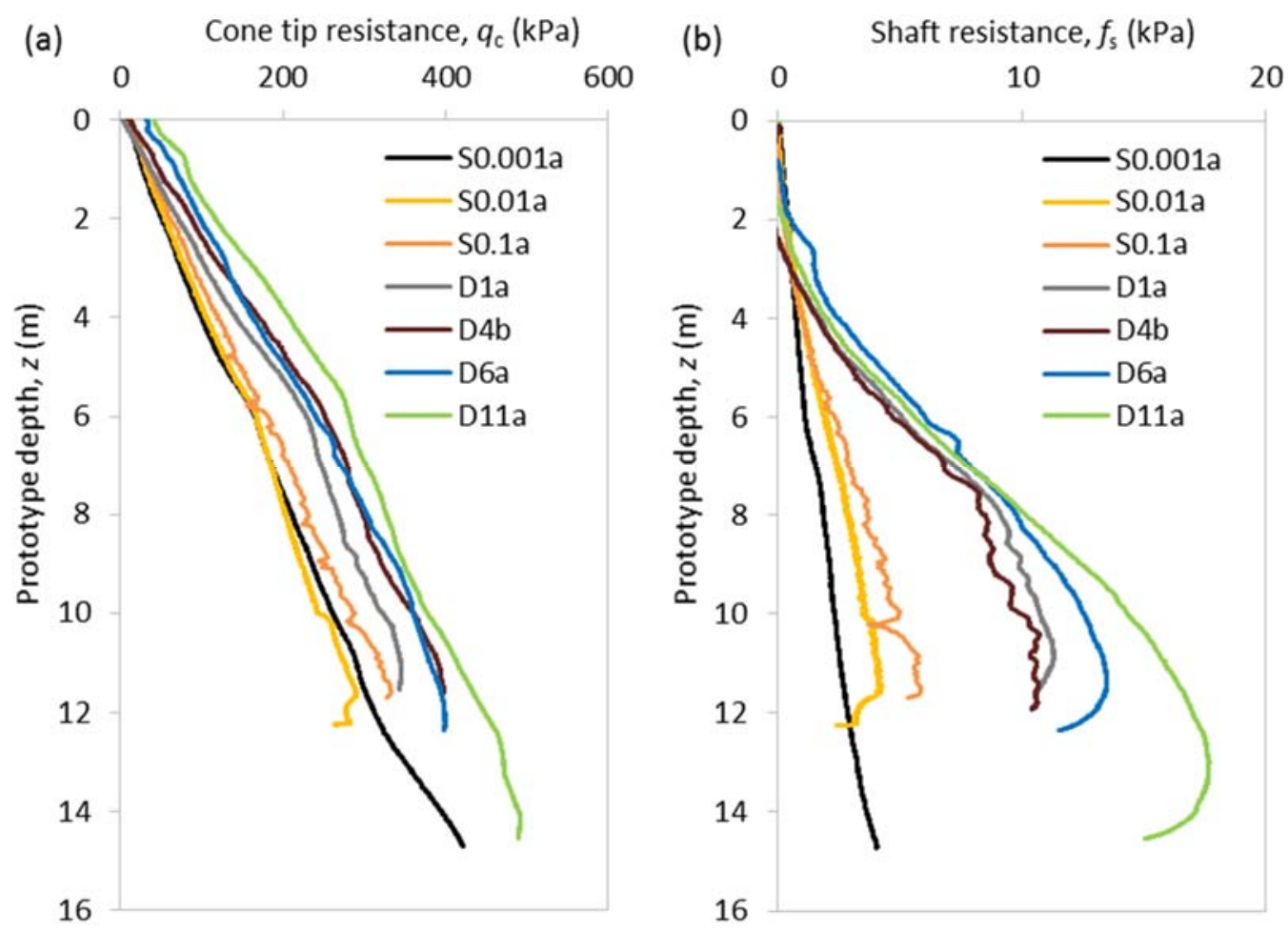

(c)

$\Delta u_{2}=u_{2}-u_{\mathrm{w}}(\mathrm{kPa})$

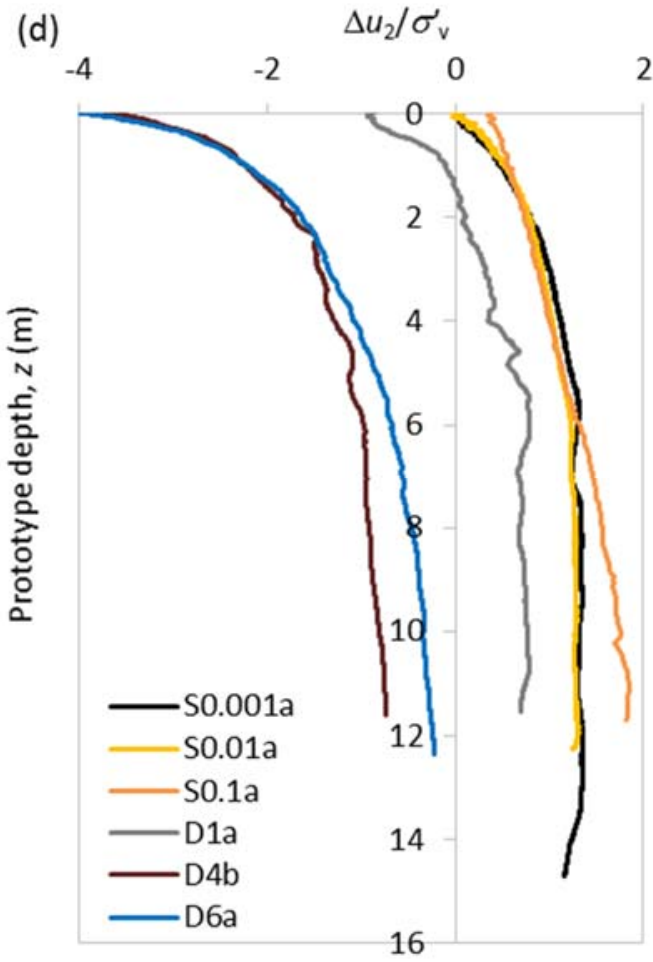

Fig. 7: (a) Cone resistance; (b) shaft resistance; (c) excess pore pressure; (d) normalised excess pore pressure profiles during penetration of static and free-fall piezocone 

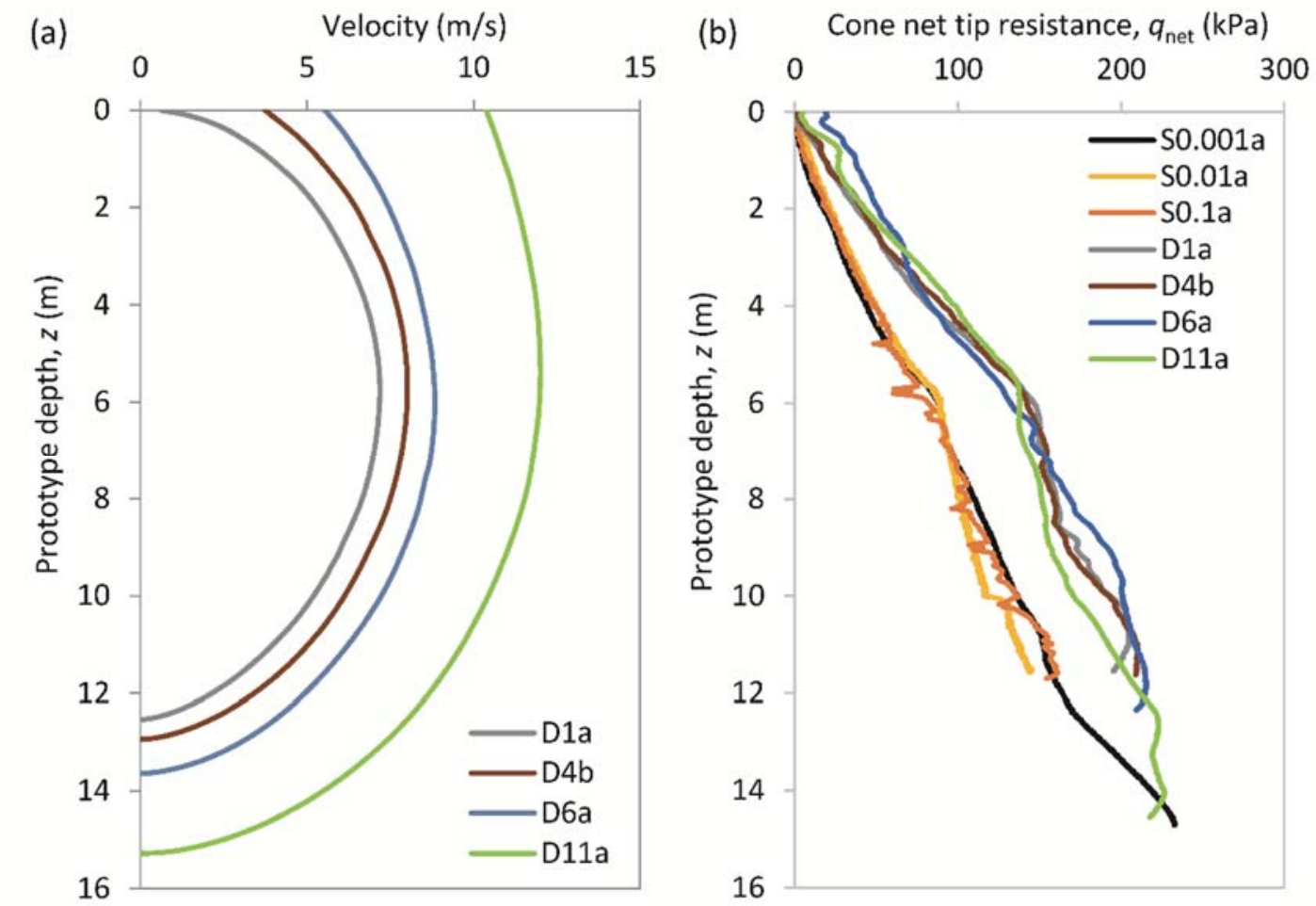

Fig. 8: (a) Velocity profiles for FFP tests; (b) cone net tip resistance profiles for piezocone and FFP tests 

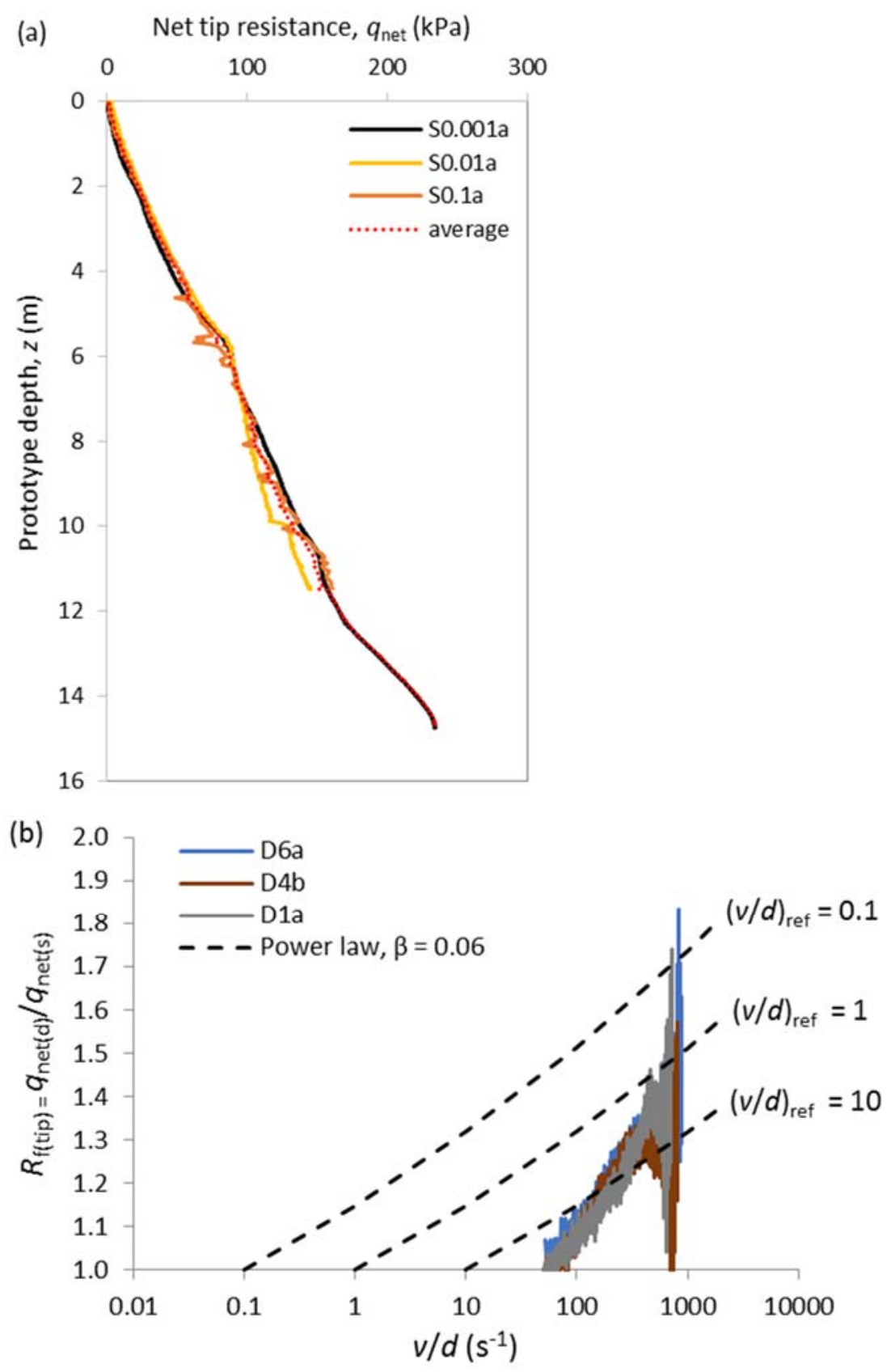

Fig. 9: (a) Average static net tip resistance profile computed from Tests S0.001a, S0.01a and S0.1a; (b) Back-calculated $R_{\mathrm{f}(\mathrm{tip})}$ using the average static net tip resistance 

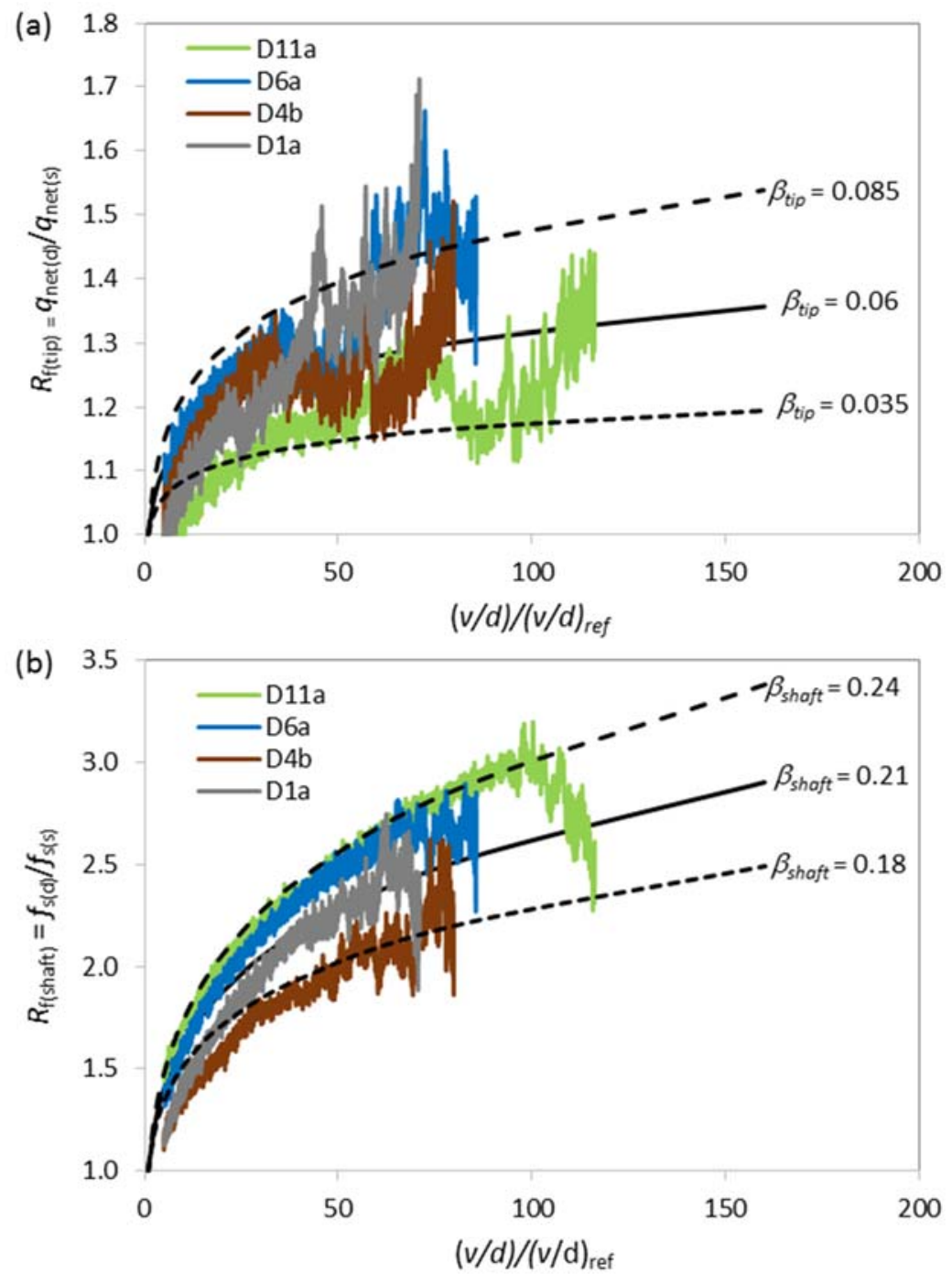

Fig. 10: Back-fitted rate parameters for (a) net tip resistance; and (b) shaft resistance using Test S0.1a as reference 

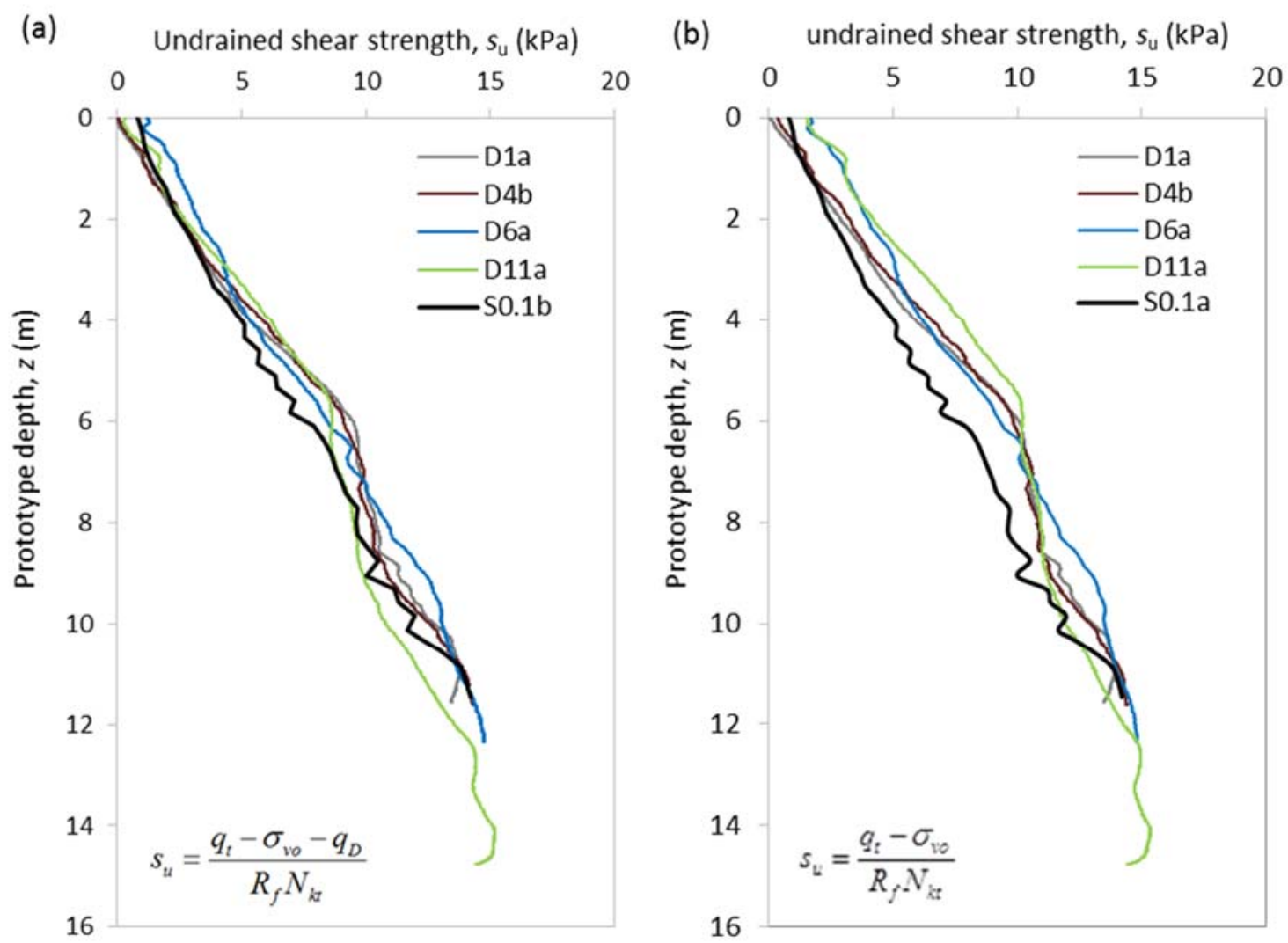

Fig. 11: Calculated $s$ u profiles using tip load cell method $\left(\beta_{\text {tip }}=0.06\right)(a)$ with correction for drag; (b) without correction for drag 
(a)

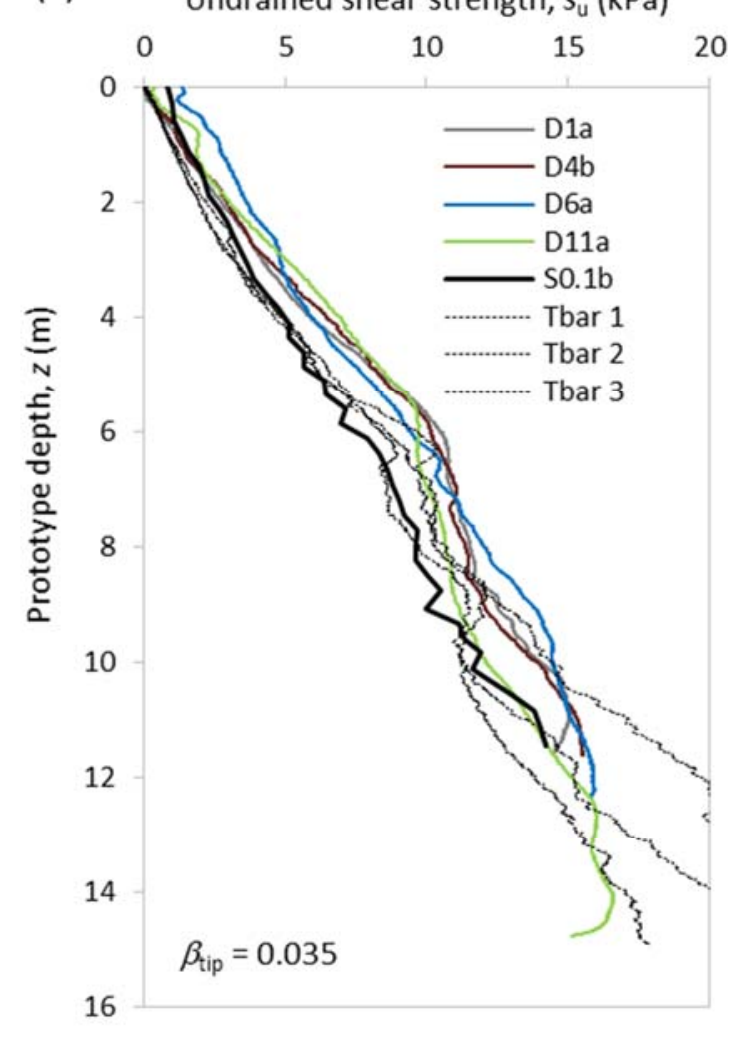

(b) Undrained shear strength, $s_{\mathrm{u}}(\mathrm{kPa})$

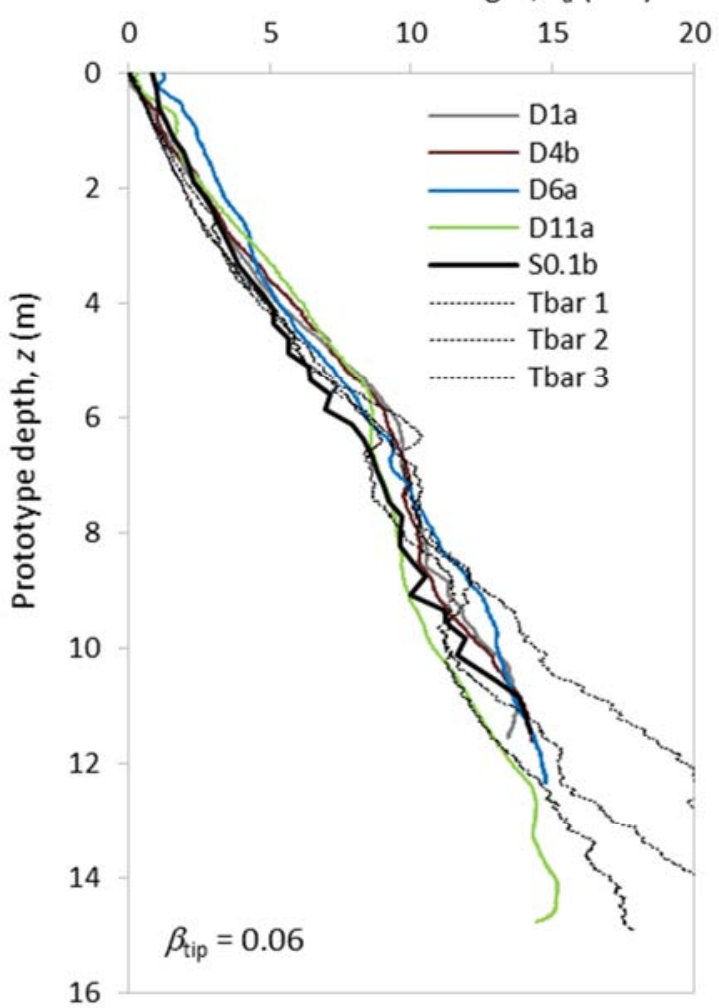

(c) Undrained shear strength, $s_{u}(\mathrm{kPa})$

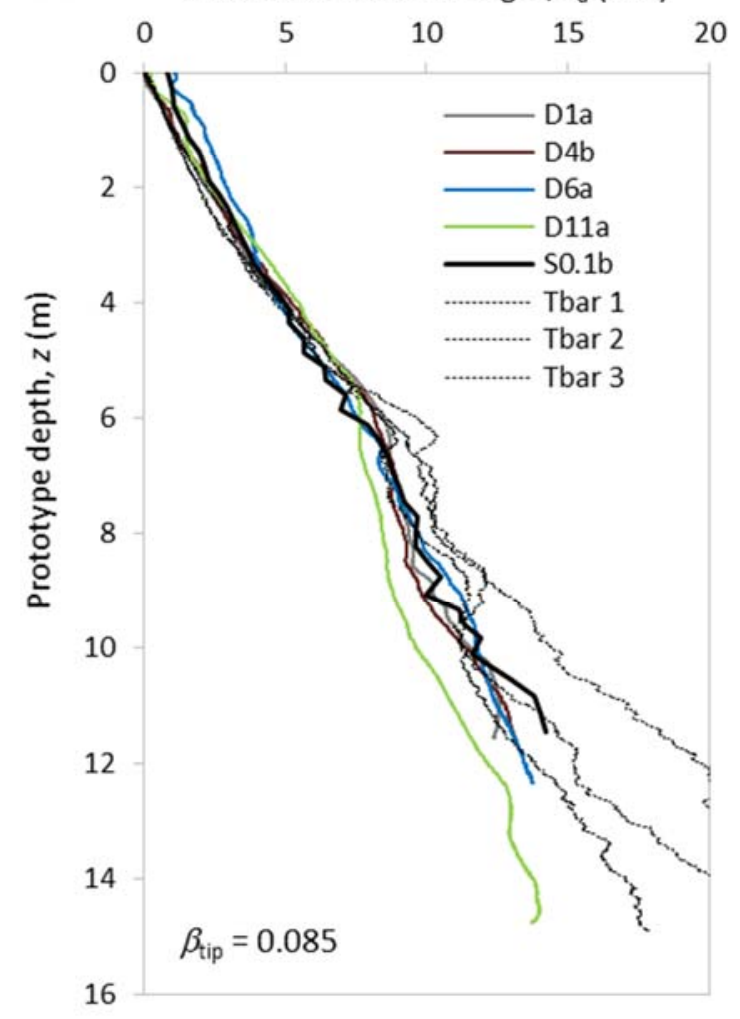

Fig. 12: Influence of rate parameter, $\beta_{\text {tip }}$ on the calculated $s_{\mathrm{u}}$ profiles using the tip load cell method: (a) $\beta_{\text {tip }}=0.035$; (b) $\beta_{\text {tip }}=0.06$; and (c) $\beta_{\text {tip }}=0.085$ 

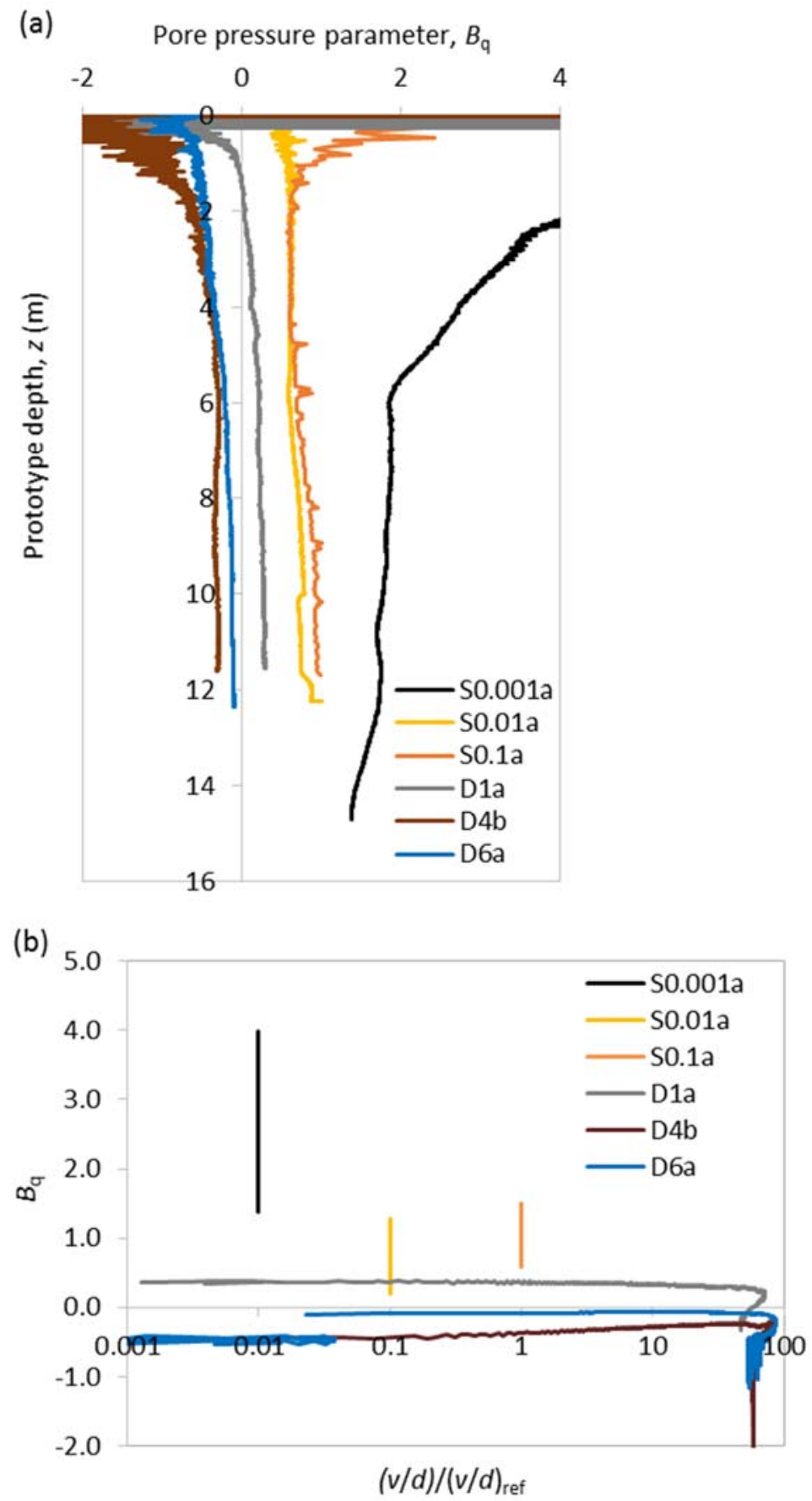

Fig. 13: Variation of $B_{\mathrm{q}}$ with: (a) depth, and (b) velocity 

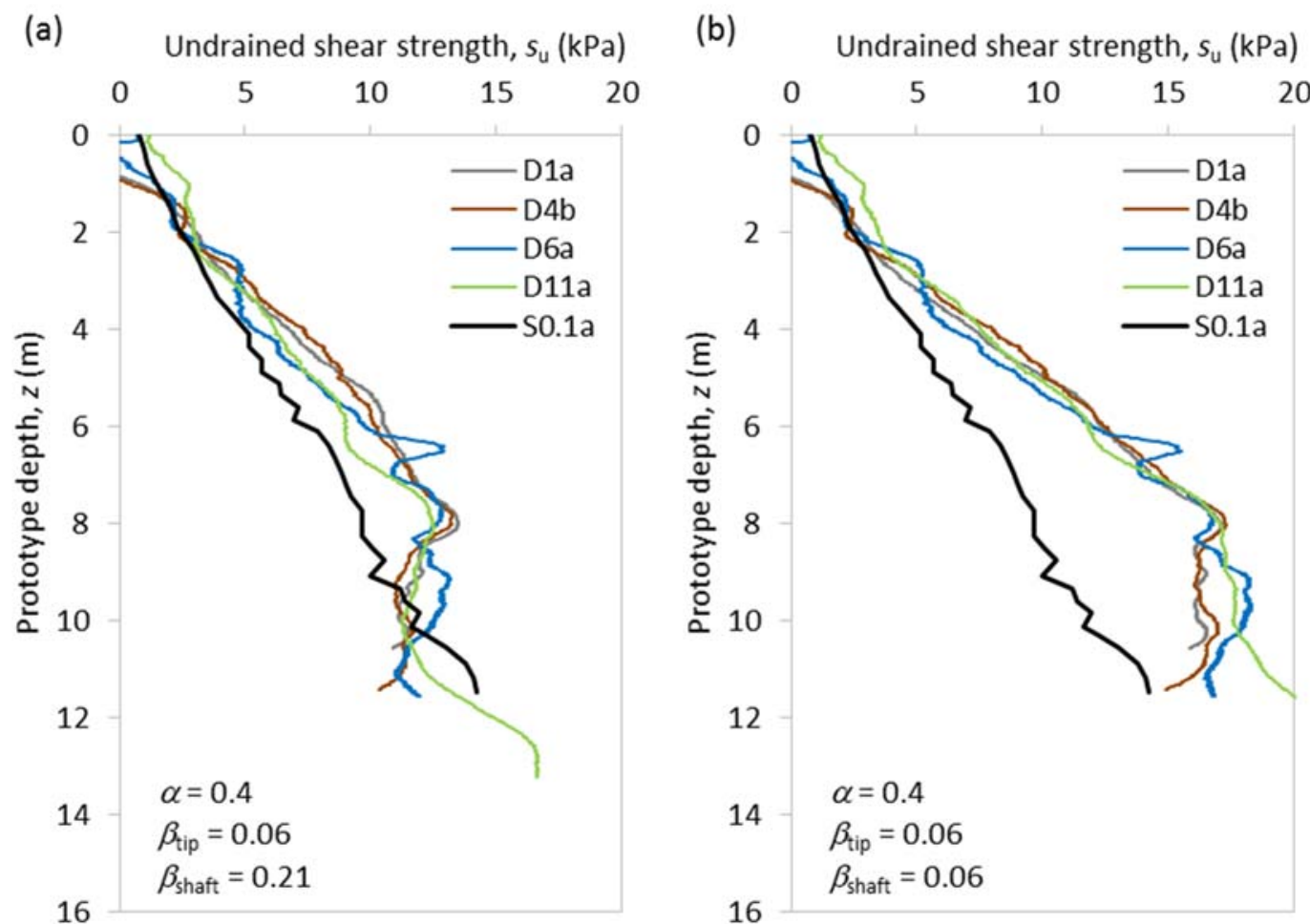

Fig. 14: FPP $s$ u profiles derived using the accelerometer method adopting:

(a) Approach 1; (b) Approach 2; 

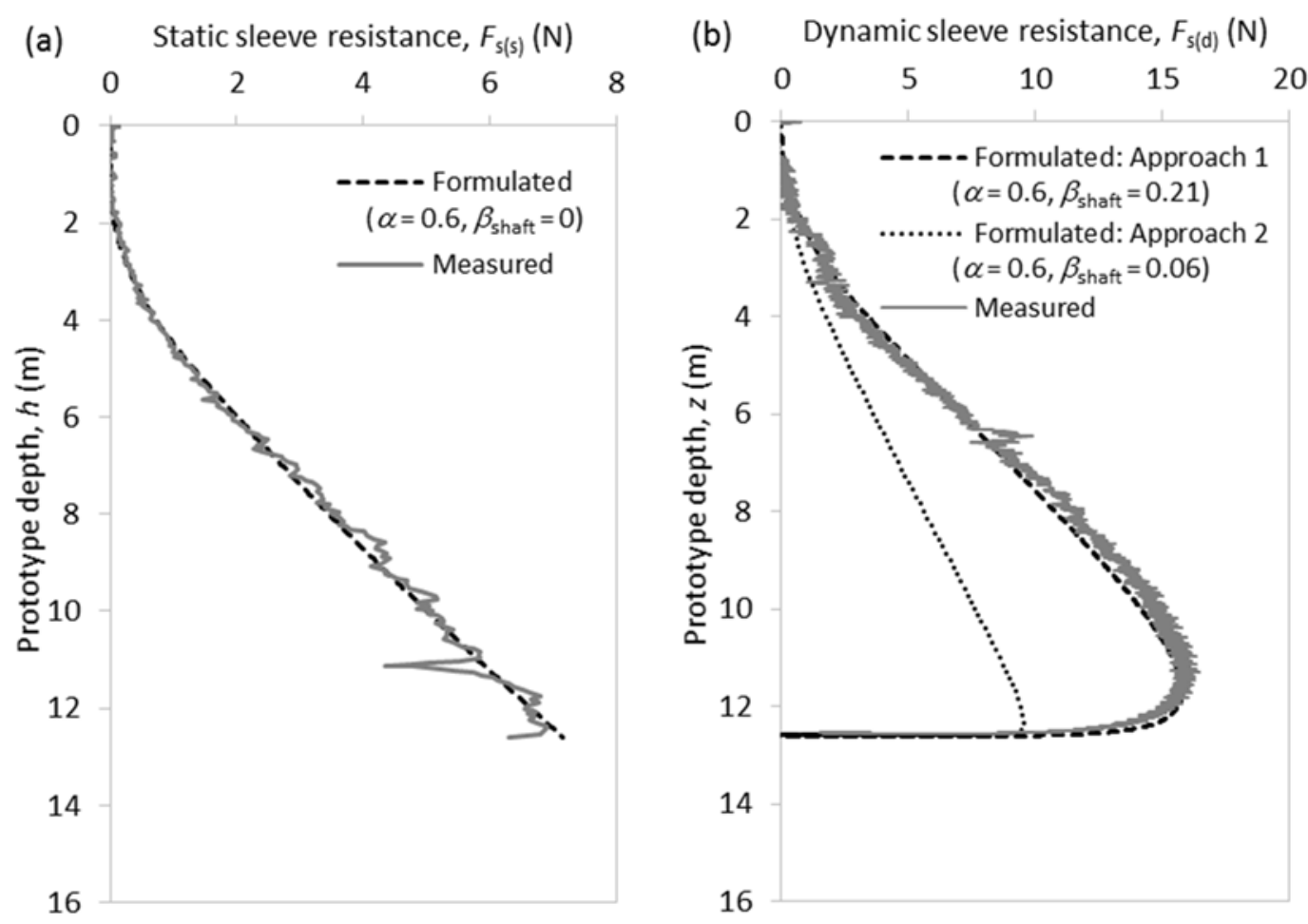

Fig. 15: Formulated and measured sleeve resistance, $F_{\mathrm{s}}$ :

(a) static case (Test S0.1b); (b) dynamic case (Test D6a) 
(a)

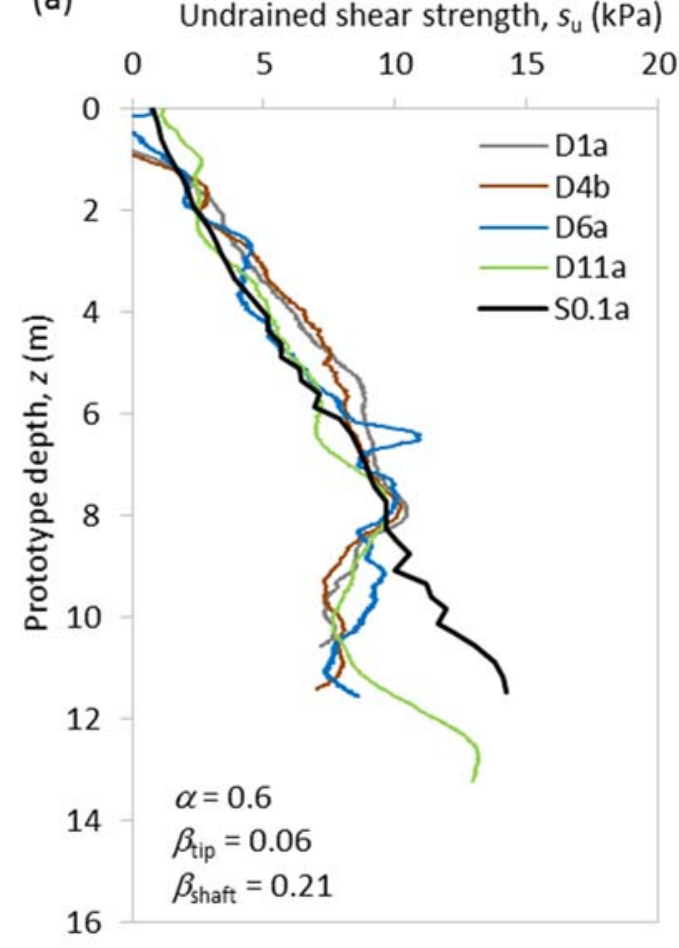

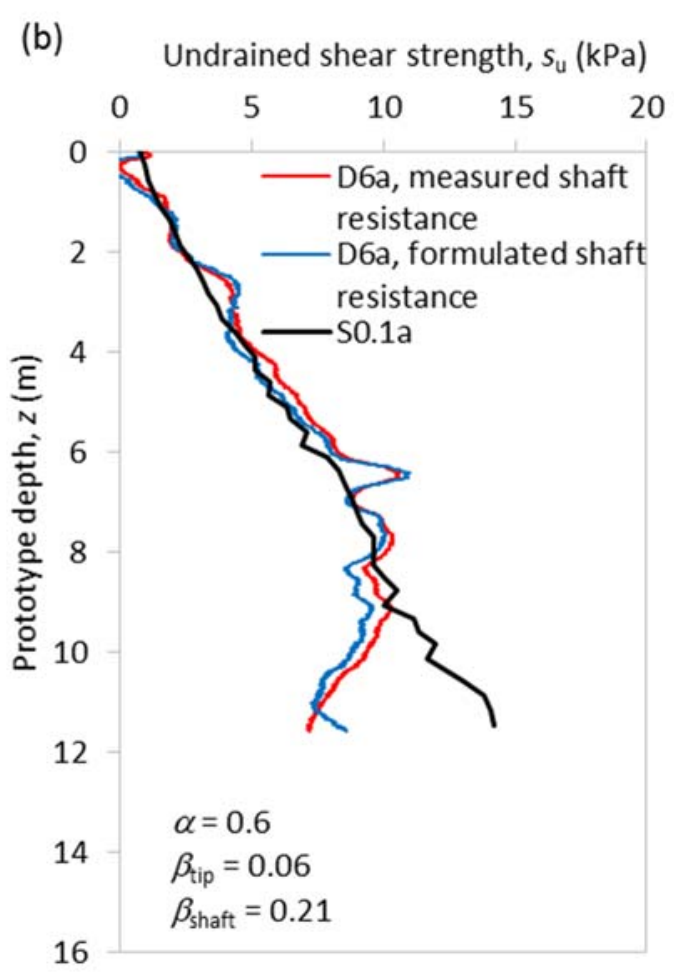

Fig. 16: Demonstrated improvements in calculated FPP $s_{\mathrm{u}}$ profiles using the accelerometer method using: (a) back-analysed $\alpha=0.6$; (b) direct measurement of dynamic shaft resistance (i.e. from shaft load cell) for test D6a 